\title{
Synergy Effect of Nitrogen and Molybdenum on Activated Carbon Matrix for Selective Adsorptive Desulfurization: Insights into Surface Chemistry Modification
}

\section{Musa O Azeez}

King Fahd University of Petroleum \& Minerals

Abdulkadir Tanimu

King Fahd University of Petroleum \& Minerals

Khalid Alhooshani

King Fahd University of Petroleum \& Minerals

Saheed A. Ganiyu ( $\sim$ gsadewale@kfupm.edu.sa )

King Fahd University of Petroleum and Minerals College of Sciences https://orcid.org/0000-00026002-3795

\section{Research Article}

Keywords: Porous granular activated carbon, nitrogen-doped carbon, molybdenum nanoparticles, selective adsorption, adsorptive desulfurization, dibenzothiophene

Posted Date: May 3rd, 2021

DOI: https://doi.org/10.21203/rs.3.rs-322025/v1

License: (c) (i) This work is licensed under a Creative Commons Attribution 4.0 International License. Read Full License 


\section{Abstract}

This study reports the synthesis of mesoporous metal-modified nitrogen doped activated carbon (AC-NMo) from date seeds by $\mathrm{ZnCl}_{2}$ activation and its applicability for selective adsorptive desulfurization of dibenzothiophene (DBT). The AC-N-Mo exhibits higher adsorption capacity for DBT at $100 \mathrm{mg}-\mathrm{S} / \mathrm{L}$ with the maximum value of $99.7 \%$ corresponding to $19.94 \mathrm{mg}-\mathrm{S} / \mathrm{g}$ at room temperature than the unmodified carbon with $17.96 \mathrm{mg}-\mathrm{S} / \mathrm{g}$ despite its highest surface area and pore volume of $1027 \mathrm{~m}^{2} \mathrm{~g}^{-1}$ and 0.55 $\mathrm{cm}^{3} \mathrm{~g}^{-1}$ respectively. The adsorption capacity breakthrough follows the order AC-N-Mo $>A C-M o>A C>A C-$ N. AC-N-Mo also displayed excellent selectivity in the presence of aromatics (toluene, naphthalene and 1methylisoquinoline). The enhancement in the DBT uptake capacities of AC-N-Mo is attributed to synergy effect of nitrogen heteroatom that aid well dispersion of molybdenum nanoparticles on carbon surface thereby improving its surface chemistry and promising textural characteristics. The kinetic studies showed that the DBT adsorption proceeds via pseudo-second order kinetics while the isotherm revealed that both Freundlich and Langmuir fit the data but Freundlich fit the data more accurately for the best performing adsorbent. The physico-chemical properties (surface area, pore volume, carbon content, particle size etc.) of as-prepared adsorbents namely; AC, AC-N, AC-N-Mo and AC-Mo were characterized by $\mathrm{N}_{2}$ - physisorption, X-ray Diffraction (XRD), X-ray Photoelectron Spectroscopy (XPS), Scanning Electron Spectroscopy/Energy Dispersive Spectroscopy (SEM/EDS), Raman Spectroscopy (RS), Fourier Transform Infrared Spectroscopy (FTIR) and Ammonia-Temperature-Programmed Desorption $\left(\mathrm{NH}_{3}\right.$-TPD).

\section{Introduction}

In fuel, sulfur compounds present combust to produce $\mathrm{SO}_{\mathrm{x}}$ resulting in acid rain and contribute to the occurrence of photochemical smog, two severe threat to the flora and fauna (Hanif et al. 2020), poisons catalytic converters used to reduce $\mathrm{CO}_{\mathrm{x}}$ and $\mathrm{NO}_{\mathrm{x}}$ in automotive engines and also causing numerous corrosion problems in pumping, pipeline, refinery equipment (Muzic et al. 2008). Owing to the deleterious impact of sulfur compounds, the concern authorities in a number of countries set stringent regulations to limit the concentration of sulfur present in industrial and transportation fuels, which becomes stricter with time. The highest permissible sulfur content has been set to $10 \mathrm{ppm}$ and $15 \mathrm{ppm}$ for gasoline and diesel oil respectively in countries like US, EU and Japan (de Lima et al. 2018).

The conventional hydrodesulfurization (HDS) technology, developed in 1930s, is largely utilized in the refineries to remove compounds of sulfur available in crude oil distillates (Song 2007). Although, HDS is an excellent desulfurization technology especially for disulfides, sulfides, thiols, and mercaptans, its activity towards thiophene and its alkylated derivatives is energy and cost intensive, especially towards achieving ultra-deep desulfurization (Sadare and Daramola 2019). HDS limitations also include severe operation conditions such as working at higher pressure and elevated temperature of 3-7 MPa and 300$400^{\circ} \mathrm{C}$ respectively, thereby resulting in excessive energy consumption. These drawbacks are unavoidable and involve significant capital investment, thus increasing fuels cost (Ghahramaninezhad and Ahmadpour 2020). A number of desulfurization technologies such as ionic liquids (ILs) desulfurization, 
adsorptive desulfurization (ADS), bio-desulfurization and oxidative desulfurization (ODS) have been adapted as an alternative and complementary process towards traditional HDS technology (Bhatia and Sharma 2012; Guo et al. 2019; Ghahramaninezhad and Ahmadpour 2020; Haghighi and Gooneh-farahani 2020; Rekos et al. 2020; Tireli et al. 2020). Meanwhile, ADS using porous adsorbents is gaining increasing attention as an alternative to achieve ultra-deep desulfurization owing to its promising characteristics that include easy accessibility of adsorbents, renewability of spent adsorbents, workability at moderate temperature and pressure, low-energy consumption, thermal stability, and satisfying textural features like elevated surface area, desirable micropores volume as well as thoroughly developed pore size (Wang et al. 2009b). Varieties of sorbent materials used in adsorptive desulfurization studies have been reported. Among others, metal organic framework (MOF), zeolites, amorphous silica-alumina, activated carbon (AC), silica gel, metal oxides, sorbents were studied for desulfurization of fluid catalytic cracking feedstock, model oils, coker naphtha and distillates (Shi et al. 2010; Ahmed and Jhung 2016; Namchot and Jitkarnka 2016).

$\mathrm{AC}$ are carbonaceous materials specially treated to give a highly-developed internal pore structure and a large surface area (Al-Qodah Z, Shawabkah 2009). Oxidation of the carbon atoms present on the interior and exterior surfaces distinguished $A C$ from the elemental carbon. The usage of non-renewable, high cost precursors namely; peat, petroleum residue, lignite, bituminous coal and wood make commercial AC expensive (Yahya et al. 2015). Thus, reasonably cheap, environmental friendly and desirable adsorbents have been investigated using agricultural by-products and waste as precursors for AC production. There is a number of reported articles that show how activated carbon surfaces were oxidized with the incorporation of metals to positively enhanced adsorption efficiency of DBTs (Ganiyu et al. 2016; Danmaliki and Saleh 2017; Olajire et al. 2017). It should be mentioned that surface chemistry modification and special treatments of AC that include both the physical and chemical modification of carbon surfaces and the treatments such as oxidation, steaming, sulfidation, acidification, metal loading and metal-oxides incorporation play essential role in adsorption capacity breakthrough as well as in the enhancement of carbon selectivity towards sulfur containing compounds (Ganiyu et al. 2016).

Xiong et al. synthesized zirconium dioxide modified activated carbon $\left(\mathrm{ZrO}_{2} / \mathrm{AC}\right)$ adsorbent and applied it for adsorptive removal of refractory sulfur compound DBT from a simulated diesel oil. The adsorption capacity of $\mathrm{ZrO}_{2} / \mathrm{AC}$ was found to outperform bare $\mathrm{AC}$ by a magnitude of $17 \%$ and the spent $\mathrm{ZrO}_{2} / \mathrm{AC}$ was found displaying a higher adsorptive capacity breakthrough than unmodified AC after recycling three times. The improved adsorption efficiency was ascribed to the surface acidic sites impregnated $\mathrm{ZrO}_{2}$ (Xiong et al. 2010). Cerium-loaded activated carbon was prepared and its applicability was studied for refractory sulfur compound removal from model fuel (dissolution of DBT in petroleum ether). The study confirmed that the cerium-loaded activated carbon showed higher adsorption selectivity and capacity for DBT compared to a virgin carbon attributed primarily to the enhanced active site created through surface chemistry modification (Xiong et al. 2012). Saleh et al. prepared four composites named as AC, AC/Ce, $\mathrm{AC} / \mathrm{Fe}$, and $\mathrm{AC} / \mathrm{Ce} / \mathrm{Fe}$ and were examined closely for the removal of organosulfur compounds of $\mathrm{DBT}$, benzothiophene (BT) and thiophene (TP) in a simulated fuel. The research confirmed that $\mathrm{AC} / \mathrm{Ce} / \mathrm{Fe}$ 
exhibited improved adsorption efficiency with the sorbent performance in the order of $\mathrm{AC}<\mathrm{AC} / \mathrm{Fe}<$ $\mathrm{AC} / \mathrm{Ce}<\mathrm{AC} / \mathrm{Ce} / \mathrm{Fe}$, despite the highest pore volume and surface area of $0.71 \mathrm{~cm}^{3} / \mathrm{g}$ and $460.27 \mathrm{~m}^{2} / \mathrm{g}$ respectively recorded for bare $\mathrm{AC}$. This excellent performance of $\mathrm{AC} / \mathrm{Ce} / \mathrm{Fe}$ was attributed to the crystalline nature of iron and acidic nature of cerium (Danmaliki and Saleh 2017).

It is established that the electronic and surface features of carbon materials can be changed via introduction of heteroatom like phosphorus, oxygen, boron and nitrogen (Fagury et al. 2014). Specifically, modification of carbon with nitrogen to form porous nitrogen-doped carbon and embedding of other heteroatoms have gained significant attention in the electrochemistry related applications (supercapacitors fuel cell, batteries, photocatalysis, etc.), as well as in catalysis, separation and water purification (Fan 2013).

Carbon-doped porous boron nitride (C-BN) was investigated for the removal of sulfur compound by Xiong and co-workers (Xiong et al. 2015). The porous C-BN showed higher adsorption efficiency for DBT as compared to boron nitride materials attributed to the stronger Lewis acid-base interactions between C$\mathrm{BN}$ and DBT molecule as well as the significant exposure of more atoms along the pores edges.

This study report the usage of synthesized metal-modified nitrogen doped AC adsorbent and its applicability for selective adsorptive desulfurization of model fuel containing the solution of dibenzothiophene in isooctane. The AC was prepared from agricultural waste material date seeds via $\mathrm{ZnCl}_{2}$ activation and subsequently treated with melamine to obtain nitrogen doped carbon. Molybdenum nanoparticle is explored owing to its acidic nature and its tendency to form direct sulfur-metal interaction with the electron donor groups containing sulfur such as DBT. Selective performance of as-developed adsorbents was also investigated on DBT in the presence of other aromatics, namely: toluene, naphthalene, and 1-methylisoquinoline. The adsorbents were extensively characterized to obtain structure-activity performance with respect to adsorbate-adsorbent interaction.

\section{Experimental}

\subsection{Materials}

Grinded Ajwa Al-Madina date seed was procured from a packaging factory in Saudi Arabia. Dibenzothiophene (99\%), 1-methylyisoquinoline, toluene were all purchased from Sigma Aldrich, while isooctane and melamine were from Fluka AG. Ammonium heptamolybdate tetrahydrate (molybdenum precursor) and zinc chloride were supplied by ACROS organics and BDH Ltd Poole England, respectively. Naphthalene was obtained from Fisher Scientific Company. Ultrapure distilled water was obtained inhouse using ThermoScientific Barnstead NANOPURE, after initial distillation through Labstrong FiSTREEMTMII 2S Glass Still distiller.

\subsection{Methods}

\subsubsection{Activated carbon (AC) preparation from date seeds}


Grinded Ajwa Al-Madina date seeds was procured from a packaging factory in Saudi Arabia and subsequently used as a precursor for $\mathrm{AC}$ production by chemical activation. Equal grams of $\mathrm{ZnCl}_{2}$ (activator) and precursor (pulverized date seeds) were measured and mixed together in a beaker. $25 \mathrm{ml}$ of distilled water was introduced into the mixture of date seeds and $\mathrm{ZnCl}_{2}$, thoroughly agitated at room temperature (RT) for $2 \mathrm{~h}$ at $600 \mathrm{rpm}$. The temperature was increased to boiling point until dryness and the stirring was reduced to $400 \mathrm{rpm}$ to allow homogeneity and prevent aggregation. The resultant mixture was transferred to an oven for further drying at $80^{\circ} \mathrm{C}$ and left overnight. The resulting sample was pyrolyzed in a horizontal silica quartz-tube of diameter $60 \mathrm{~mm} \times 1000 \mathrm{~mm}$ length and inserted in an electric $1200{ }^{\circ} \mathrm{C}$ compact split tube furnace MTI (OTF-1200X-S) set at $950^{\circ} \mathrm{C}$ using heating rate of $5{ }^{\circ} \mathrm{C} / \mathrm{min}$, flow rate of $300 \mathrm{~mL} / \mathrm{min}$ and maintained at this temperature for $3 \mathrm{~h}$ to allow the complete carbonization. Ultimately, the sample was cooled to room temperate under $\mathrm{N}_{2}(99.95 \%)$ at the same flow rate before it was removed from the furnace. The as-prepared pristine activated carbon was therefore denoted as AC.

\subsubsection{Preparation of nitrogen-doped activated carbon (AC-N)}

As-developed activated carbon and melamine were subjected to solid state impregnation and thermal spreading by direct mixing of the duo in ratio of 2 to 1 by weight (melamine/AC $=2$ ). The sample mixture was heated up to $900{ }^{\circ} \mathrm{C}$ at $10^{\circ} \mathrm{C} /$ min under $\mathrm{N}_{2}(99.95 \%)$ for a hold time of $2 \mathrm{~h}$. The resulting sample was cool to RT under $\mathrm{N}_{2}$ at the same flow rate before it was removed from the furnace.

\subsubsection{Synthesis of Mo-modified nitrogen-doped carbon (AC-N-Mo) and Mo-loaded activated carbon (AC- Mo)}

$2.5 \mathrm{wt} \%$ molybdenum was loaded into nitrogen-doped AC via solid state impregnation and thermal spreading. This is achieved by direct mixing of $0.023 \mathrm{~g}$ of molybdenum $\left.\left(\mathrm{NH}_{4}\right)_{6} \mathrm{Mo}_{7} \mathrm{O}_{24} \cdot 4 \mathrm{H}_{2} \mathrm{O}\right)$ with $1.0 \mathrm{~g}$ of AC-N and the resultant mixture was treated under the continuous flow of $\mathrm{N}_{2}(99.95 \%)$ and was heated up to $600^{\circ} \mathrm{C}$ at $10^{\circ} \mathrm{C} / \mathrm{min}$ for a hold time of $1 \mathrm{~h}$. To obtain Mo-loaded activated carbon (AC-Mo), the above procedure was repeated using virgin AC.

\subsection{Characterization of as-synthesized adsorbents}

\subsubsection{BET analysis}

Surface area and pore volume analysis of the adsorbent were determined by $\mathrm{N}_{2}$ adsorption-desorption isotherms by employing BET and BJH-adsorption methods respectively. Samples were analyzed at boiling point of liquid nitrogen $\left(-196^{\circ} \mathrm{C}\right)$, on a Micrometrics ASAP 2020 equipped with chemisorption set (Micrometrics, USA) after degassing at $300^{\circ} \mathrm{C}$ for $3 \mathrm{~h}$ (ramping at $10^{\circ} \mathrm{C} / \mathrm{min}$ ) to remove impurities and moisture under vacuum.

\subsubsection{X-ray diffraction (XRD)}


X-ray Diffraction analysis was done on Rigaku Ultima IV X-ray diffractometer using Ka radiation of Cu by recording the adsorbents diffraction pattern at $2 \theta$ angle between $10^{\circ}$ to $60^{\circ}$, and stepwise of 0.03 . The operation was conducted at $40 \mathrm{kv}$ and $40 \mathrm{~mA}$ with a scan rates of $3 \% \mathrm{~min}$.

\subsubsection{Fourier transform infrared spectroscopy (FT-IR)}

Surface functional groups of the prepared adsorbents was investigated by FTIR using Thermo Scientific Nicolet $^{\mathrm{Tm}} \mathbf{6 7 0 0}$ FT-IR spectrometer model equipped with deuterated triglycine sulfate detector and OMNIC program. Samples were pelletized with the aid of $\mathrm{KBr}$ in right proportion (2: 100 of sample to $\mathrm{KBr}$ ) in an agate mortar, and spectra was obtained while correcting for the background noise and recorded by adding 64 scans with a resolution of $2 \mathrm{~cm}^{-1}$ at scanning range of $400-4000 \mathrm{~cm}^{-1}$.

\subsubsection{Scanning electron microscopy coupled with energy dispersive x-ray (SEM-EDX)}

SEM analysis was carried out at an accelerating voltage of $30 \mathrm{kV}$ using secondary electron (SE) and back scattered electron (BSE) mode on the adsorbents to investigate porosity development with high vacuum Thermo Scientific ${ }^{T M}$ Quattro ESEM equipped with electron gun and attached to EDS (Oxford, Inc.). EDS was employed for the identification of elemental composition in and on the surface of the sample for qualitative information

\subsubsection{X-ray photoelectron spectroscopy (XPS)}

XPS, 250Xi ESCALAB Thermo Scientific equipped with (PHI 5000 Versa Probe II, ULVAC-PHI Inc.) using Al $\mathrm{Ka}$ as radiation source. Samples were prepared by mixing the adsorbent with ethanol in drop-wise addition of the solvent, then deposited on glass with the aid of pipette and allowed to air-dry. The samples were mounted on the carbon tape and vacuum prior to XPS analysis at $9 \times 10^{-8} \mathrm{mBar}$ as analysis chamber vacuum, and deconvolution of peaks was done by Avantage software with adventitious carbon correction at $284.8 \mathrm{eV}$.

\subsubsection{Raman spectroscopy (RS)}

RS analysis was conducted on the prepared adsorbents using (iHR320 with CCD detector, HORIBA) to analyze functional groups fingerprint on the adsorbents with regards to graphitization or amorphous nature by measuring the energy released from scattered photons when the adsorbents were exposed to monochromatic light from a wavelength (300 mW, green laser), laser $(532 \mathrm{~nm})$ observed via rotational, translational and vibrational modes produced.

\subsubsection{Ammonia temperature programmed desorption $\left(\mathrm{NH}_{3}-\mathrm{TPD}\right)$}

$\mathrm{NH}_{3}$-TPD was conducted to understand and analyze the acidic sites that are present on the adsorbent surface. This analysis (performed on Micromeritics AutoChem II 2920, Chemisorption Analyzer) was conducted by loading roughly $100 \mathrm{mg}$ of the adsorbents in a quartz tube sealed with cotton wool. Before the analysis, samples were degassed at $100{ }^{\circ} \mathrm{C}$ for $30 \mathrm{~min}$ in flowing helium $(20 \mathrm{~mL} / \mathrm{min})$ to remove 
water vapor. Thereafter, the temperature was raised to $500{ }^{\circ} \mathrm{C}$ at a ramp rate of $10{ }^{\circ} \mathrm{C} / \mathrm{min}$ and held at that temperature for $1 \mathrm{~h}$ to remove strongly bound species. The samples were subsequently cooled to 100 ${ }^{\circ} \mathrm{C}$ under the fixed flow of helium gas. The adsorption process begins by saturating the samples with 10 wt $\% \mathrm{NH}_{3}$ gas for 30 min at $100{ }^{\circ} \mathrm{C}$ at the flowrate of $30 \mathrm{~mL} / \mathrm{min}$ and the excess $\mathrm{NH}_{3}$ was expelled by flushing with helium gas for $60 \mathrm{~min}$ at the same temperature. Subsequently, the temperature was raised to $900{ }^{\circ} \mathrm{C}$ at $10{ }^{\circ} \mathrm{C} / \mathrm{min}$ and under these conditions; the amount of ammonia desorbed at the ramping temperatures was recorded using the thermal conductivity detector (TCD).

\subsection{Adsorption Experiment}

To evaluate adsorptive performance of the adsorbents, ADS of a simulated fuel was conducted in batch mode using DBT as the analyte. Various concentration (50 - $200 \mathrm{mg}-\mathrm{S} / \mathrm{L}$ ) of DBT in isooctane were prepared. In a typical run, $20 \mathrm{~mL}$ of the simulated oil of each concentration and adsorbent amounts range from $0.025 \mathrm{~g}-0.1 \mathrm{~g}$ were added in a capped vial and then subjected to continuous constant shaking at the rate of $600 \mathrm{rpm}$ on a magnetic stirrer (IKA RT 10) maintained at room temperature $\left(25^{\circ} \mathrm{C} \pm 0.1^{\circ} \mathrm{C}\right)$ for a fixed time interval of $24 \mathrm{~h}$ maximum. The sampling was done at $15 \mathrm{~min}$ interval for the first $30 \mathrm{~min}$ using a syringe coupled with a membrane filter for determination of residual DBT concentration evaluated by gas chromatography (Agilent 7890A) coupled with SCD (Agilent 355) within the experimental error of $2 \%$. To compare and study the adsorptive selectivity for organo-sulfur and nitrogen compound, a model diesel fuel containing naphthalene ( $5 \mathrm{vol} \%$ ), toluene ( 5 and $10 \mathrm{vol} \%$ ), and $100 \mathrm{mg} / \mathrm{L}$ of 1-methylisoquinoline were prepared in a mixture solvent of DBT and adsorption studies were carried out at the stated working condition.

The DBT adsorption $\left(\mathrm{q}_{\mathrm{e}}, \mathrm{mg} / \mathrm{g}\right)$ at equilibrium was calculated with the formula stated below;

$$
q_{e}=\left(C_{0}-C_{e}\right) \frac{V}{W} \quad \ldots \ldots \ldots \ldots . . .1
$$

Where $\mathrm{V}$ measures in liter and represent the volume of model fuel solution, $\mathrm{W}(\mathrm{g})$ denotes weight of the adsorbent and $\mathrm{Co}(\mathrm{mg} / \mathrm{L})$ and $\mathrm{Ce}(\mathrm{mg} / \mathrm{L})$ are initial and equilibrium sulfur concentration respectively.

\section{Results And Discussion}

\subsection{Surface area and porosity}

$\mathrm{AC}$ are usually microporous materials thus limiting their application to studies involving small molecules such as methanol production from $\mathrm{CO}_{2}$ and hydrogen (Abotsi and Scaroni 1989). Recent applications of activated carbon require higher percentage of mesoporosity to facilitate diffusion of larger molecules in order to attain effective adsorption efficiency (By Zhonghua Hu, Madapusi P. Srinivasan and Ni 2000). Thus, commendable efforts have been directed towards creation of mesoporosity into AC for extensive applications (Moosavi et al. 2012). The nitrogen adsorption - desorption isotherm of AC, AC-N, AC-N-Mo 
and AC-Mo are shown in Fig.1A. The samples show typical type IV isotherms with an H4 hysteresis loop in accordance to IUPAC classification (K. S. W. Sing, D. H. Everett, R. A. W. Haul, L. Moscou, R. A. Pierotti, J. Rouquérol 1985). H4 loops are often found in micro-mesoporous carbon (K. S. W. Sing, D. H. Everett, R. A. W. Haul, L. Moscou, R. A. Pierotti, J. Rouquérol 1985). It was observed that the four samples showed a low uptake of nitrogen at relative pressures below 0.1 indicating the availability of micropores within the samples. A hysteresis loop was also seen at high relative pressure between 0.4-1, indicating mesoporosity (Min and Harris 2006; Danmaliki and Saleh 2017). Table 1 summarizes the textural properties of all prepared adsorbents. The pure AC has the highest surface area of $1026.77 \mathrm{~m}^{2} / \mathrm{g}$ with almost 70\% mesoporosity. Doping of nitrogen and loading of Mo onto AC's surface drastically lowered the pore volume and the overall surface area but increased mesoporosity to about $72 \%$. AC-Mo gave the least pore volume and surface area as evidenced in the Table 1 . This reduction in the surface area and pore volume was as a result of pore blockage (Ganiyu et al. 2016).

Table 1 Surface area and pore characteristics

\begin{tabular}{|c|c|c|c|c|c|c|c|}
\hline Adsorbents & $\begin{array}{c}\text { BET } \\
\text { surface } \\
\text { area } \\
\left(\mathrm{m}^{2} / \mathrm{g}\right)\end{array}$ & $\begin{array}{l}\text { Microporous } \\
\text { surface } \\
\text { area } \\
\left(\mathrm{m}^{2} / \mathrm{g}\right)\end{array}$ & $\begin{array}{c}\text { Mesoporous } \\
\text { surface } \\
\text { area } \\
\left(\mathrm{m}^{2} / \mathrm{g}\right)\end{array}$ & $\begin{array}{c}\text { Microporous } \\
\text { pore } \\
\text { volume } \\
\left(\mathrm{cm}^{3} / \mathrm{g}\right)\end{array}$ & $\begin{array}{c}\text { Total } \\
\text { pore } \\
\text { volume } \\
\left(\mathrm{cm}^{3} / \mathrm{g}\right)\end{array}$ & $\begin{array}{l}\text { Average } \\
\text { pore } \\
\text { size } \\
(\mathrm{nm})\end{array}$ & $\mathrm{R}=\mathrm{I}_{\mathrm{D}} / \mathrm{I}_{\mathrm{G}}$ \\
\hline $\mathrm{AC}$ & 1027 & 313 & 714 & 0.14 & 0.55 & 2.14 & 1.17 \\
\hline$A C-N$ & 886 & 300 & 636 & 0.11 & 0.48 & 2.18 & 1.20 \\
\hline AC-N-Mo & 885 & 251 & 634 & 0.11 & 0.48 & 2.20 & 1.22 \\
\hline AC-Mo & 830 & 236 & 594 & 0.10 & 0.45 & 2.18 & 1.19 \\
\hline
\end{tabular}

\subsection{XRD pattern of parent activated carbon and the treated AC}

$\mathrm{XRD}$ is a crucial characterization tool often employed for phase identification of unknown crystalline materials (e.g. minerals, inorganic compounds). Atom has a clear-cut diffraction patterns that is seen upon exposure to X-ray beam. It is obvious from the Fig. 1B below, indicating XRD patterns of AC, AC-N, AC-N-Mo and AC-Mo that all the adsorbents showed a broad diffuse peaks at $2 \theta$ around $24^{\circ}$ and $43^{\circ}$, assigned to the (002) and (100) reflection planes, indicating the amorphous nature of the ACs (Mahadevan et al. 2012). These peaks resulted from the pores created due to carbon decomposition in the direction of graphitic structures that proved semi-crystalline nature (Danmaliki and Saleh 2017). Also, AC crystallite structure is characterized with the interlayer spacing $\left(\mathrm{d}_{002}\right)$ (Roh 2008). The (100) reflection correlate with the honeycomb structure formed by $\mathrm{sp}^{2}$ hybridized carbon (Geng et al. 2011). However, heteroatom $(\mathrm{N})$ activation of activated carbon causes defect sites and modification in the carbon lattice thereby boosted the crystallinity of treated ACs and this agrees with the result of FTIR analysis as evidenced in the intensity of $\mathrm{C}-\mathrm{N}$ and $\mathrm{C}=\mathrm{N}\left(1640 \mathrm{~cm}^{-1}\right.$ and $1564 \mathrm{~cm}^{-1}$ respectively). In addition, the corresponding peaks of Mo on the adsorbents AC-N-Mo and AC-Mo were assigned accordingly. The 
intensity diffraction peaks of $\mathrm{Mo}$ at $2 \theta\left(^{\circ}\right)=25.7$ and 53.2 are typical of $\mathrm{MoO}_{2}$ and low intensity diffraction peak at $2 \theta=37^{\circ}$ is typical of $\beta-\mathrm{Mo}_{2} \mathrm{C}$ in accordance with Joint Committee on Powder Diffraction Standards (JCPDS No 11-0680) (Puello-polo 2014). This further showed that Mo was successfully loaded on carbon surfaces. These Mo peaks are confirmed in the XPS and $\mathrm{NH}_{3}$-TPD results.

\subsection{Raman Spectroscopy of AC and modified sorbents}

Two clear G-band and D-band peaks corresponding to $E_{2 g}$ and $A_{i g}$ respectively are observed in the Raman spectra of untreated activated carbon (AC) and modified activated carbons AC-N, AC-N-Mo and AC-Mo with the first peaks at $\left(1595 \mathrm{~cm}^{-1}\right)$, the G-peak ascribed to the scattering peak of graphite and the D-band peak near $\left(1340 \mathrm{~cm}^{-1}\right)$ is seen as a result of disordered arrangement, lattice defects and low symmetry carbon structure of graphite (Liu et al. 2017) (Fig. 1C). These two sharp peaks suggested that AC material contains of typical amorphous structures and is confirmed by the XRD results as indicated by broad diffuse peaks observed around $24^{\circ}$ assigned to (002) seen in amorphous carbon. The degree of graphitization can be estimated with respect to D-peak intensities relative to G-peak intensities using the below expression

$$
R=\frac{I_{D}}{I_{G}} \ldots \ldots \ldots \ldots \ldots . . .2
$$

Where $I_{D}$ and $I_{G}$ represent $D$-band and G-band intensity respectively and $R$ denotes the degree of graphitization. The higher the degree of graphitization, the smaller the $R$ value (Liu et al. 2017). The same pattern were observed in the Raman spectral of all the prepared samples describing an indication of qualitative existence of the disordered structure, a popular characteristics for AC materials (Roh 2008). Synthesized adsorbents AC, AC-N, AC-N-Mo and AC-Mo have R values corresponding to 1.17, 1.20, 1.22, and 1.19 respectively. This shows that $A C$ and $A C-M o$ have higher degree of graphitization with little or no defects.

\subsection{Fourier transform infrared spectroscopy (FTIR)}

A non-destructive spectroscopy techniques such as FTIR, usually employed to show energy level of the substance, atomic or molecular structure via electromagnetic interaction effect (Aging and Munajad 2018). FTIR analysis as presented in Fig. 1D gave chemical identification about the characteristics functional groups using an infrared spectrum the materials absorbed. It is clear that all the spectral follow similar pattern except that slight changes were observed in the peak intensities of some functional groups that are within the expectations. The medium sharp peak at $3734 \mathrm{~cm}^{-1}$ is attributed to $\mathrm{O}-\mathrm{H}$ stretching vibration of free alcohols (Tironi et al. 2012). The strong broad band observed at $3430 \mathrm{~cm}^{-1}$ in all the samples were assigned to $\mathrm{O}-\mathrm{H}$ stretching vibrations of hydroxyl or carboxylic group or perhaps due to chemisorbed water (Danmaliki and Saleh 2017). Similarly, well resolved sharp peaks were seen in all 
the adsorbents at $2852 \mathrm{~cm}^{-1}$ and $2920 \mathrm{~cm}^{-1}$ associated to aliphatic $\mathrm{C}-\mathrm{H}$ stretching vibration of $\mathrm{CH}, \mathrm{CH}_{2}$ and $\mathrm{CH}_{3}$ (Danmaliki and Saleh 2017). A characteristic sharp and strong peak of $\mathrm{O}=\mathrm{C}=\mathrm{O}$ was also observed at $2360 \mathrm{~cm}^{-1}$. Broad peak observed at $1735 \mathrm{~cm}^{-1}$ is assigned to $\mathrm{C}=0$ stretching vibration of sixmembered ring lactones (Coates 2006). The medium peak at $1640 \mathrm{~cm}^{-1}$ and $1564 \mathrm{~cm}^{-1}$ can be ascribed to $\mathrm{C}-\mathrm{N}$ and $\mathrm{C}=\mathrm{N}$ heterocycles (Lan et al. 2019). This medium peak is pronounced only in AC-N and AC-NMo such that it furthers support the dispersion of heteroatom $(\mathrm{N})$ on carbon surfaces. The peak at 1090 $\mathrm{cm}^{-1}$ is a characteristics of amorphous carbon and is attributed to $\mathrm{C}-\mathrm{O}$ stretching vibration (Danmaliki and Saleh 2017). This is why parent AC gave the highest intensity of this peak but upon modification with $N$ and Mo the intensities decreased. The peak at $690 \mathrm{~cm}^{-1}$ corresponds to $\mathrm{C}-\mathrm{H}$ bend of mono-substitution (phenyl)(Coates 2006) and these peaks only observed in all the adsorbents except in pure carbon, indicating that the modification on carbon increased the acidic sites on carbon surfaces. The last peak at the fingerprint region is centered at $468 \mathrm{~cm}^{-1}$ and is assigned to bending mode on Mo-O-Mo vibration entity (Bojidarka Ivanova 2011). These peaks were observed only in AC-N-Mo and AC-Mo and reflect that Mo was successfully loaded on carbon surface. This result is in close proximity with the result obtained in XRD, XPS, BET/EDS, and TPD as it confirms the presence of oxygen-containing functional groups.

\subsection{SEM and EDS of as-synthesized sorbents}

The porosity and elemental composition of the prepared adsorbents were examined with SEM/EDS, and micrograph of the synthesized adsorbents are presented in Fig. 2 and Fig. SI-1. These adsorbents show differences in the degree and nature of porosity owing to modification of surface chemistry of AC-N, AC$\mathrm{N}-\mathrm{Mo}$ and $\mathrm{AC}-\mathrm{Mo}$ when compared with a pure AC derived from date seeds. AC is a diverse adsorbent containing up to $90 \%$ carbon with a unique properties of high surface area and high degree of porosity (Yahya et al. 2015) and this fact was seen to hold in all the adsorbents, as above $90 \mathrm{wt} \%$ carbon were recorded in all. Fig. 5 (a) shows carbon and oxygen corresponding to parent AC from date seeds. It has the highest oxygen content of $5.1 \mathrm{wt} \%$ but slightly decreases upon nitrogen and metal loading on the surface of the adsorbent due to deposition of nanoparticles. Dispersion of heteroatom $(\mathrm{N})$ and Mo on the AC surface increased the porosity as observed in the corresponding SEM micrograph and this agrees with the BET and FTIR results. It is also obvious from the EDS result that nitrogen and metal loading for AC-NMo have $2.8 \mathrm{wt} \%$ and $1.1 \mathrm{wt} \%$ respectively, an indication of sufficient dispersion of heteroatom $(\mathrm{N})$ and successful metal loading. The EDS mapping (not shown) shows that both $\mathrm{N}$ and Mo are uniformly distributed yet devoid of particles agglomeration. Thus, further explained why AC-N-Mo appeared the best performing adsorbent.

\subsection{X-ray photoelectron spectroscopy (XPS)}

The XPS analysis of pure carbon and modified mesoporous carbon (AC, AC-N and AC-N-Mo,) presented in Fig. 3 ( $a, b$, and $c$ ) respectively prove the presence of $C, N, O$ in all the as-developed adsorbents. Additionally, Molybdenum peaks were also seen in the AC-N-Mo and AC-Mo. Two different peaks were observed in the deconvoluted spectrum of carbon in all the adsorbents with the binding energy peaks at 
284.5 and $283 \mathrm{eV}$ respectively. The peaks at $284.5 \mathrm{eV}$ corresponds to C-C bond ( $\mathrm{sp}^{2}$ ) (Lo et al. 2013) but the second $\mathrm{C} 1 \mathrm{~s}$ peak at $283 \mathrm{eV}$ is also $\mathrm{sp}^{2}$ carbon but shifted to lower $\mathrm{BE}$. The deconvoluted nitrogen spectrum N1s also shows one nitrogen state for AC-N at $396 \mathrm{eV}$ corresponding to nitride nitrogen and three different nitrogen states were seen in the deconvoluted spectrum of AC-N-Mo adsorbent at N1s (398 $\mathrm{eV}), \mathrm{N} 1 \mathrm{~s}(396 \mathrm{eV})$ and $\mathrm{N} 1 \mathrm{~s}(401.6 \mathrm{eV})$ which correspond to pyridinic $\mathrm{N}$, nitride nitrogen and graphitic nitrogen ( $\mathrm{N}-\mathrm{C}=\mathrm{O}$ ) respectively (Sobol et al.; Kim et al. 2012; Fu et al. 2016). The AC, AC-N and AC-N-Mo adsorbents show $01 \mathrm{~s}$ peak at $530.9 \mathrm{eV}, 530.8 \mathrm{eV} 531 \mathrm{eV}$ respectively, all were attributed to the oxygen bond state in $\mathrm{C}=\mathrm{O}$ in quinones, carbonyl group (Sobol et al.; Lo et al. 2013). In AC-Mo adsorbent, 01s peak was observed at $530.2 \mathrm{eV}$ assigned to oxygen bond state in metal oxide Mo-0. The Mod3 deconvoluted spectrum of AC-N-Mo shows three Mo chemical states $227.8 \mathrm{eV}, 230.8 \mathrm{eV}$ and $233 \mathrm{eV}$ correspond to molybdenum states in $\mathrm{Mo}_{2} \mathrm{C}, \mathrm{MoO}_{3}$ and $\left(\mathrm{NH}_{4}\right) \mathrm{MoO}_{4}$ respectively. As shown in Table SI-1 AC-N-Mo has the highest oxygen percent. This further support the reason AC-N-Mo showed the best adsorption capacity towards the DBT. This result confirmed that the adsorption capacity breakthrough of AC-N-Mo is also due to the attachment of oxygen containing functional groups onto the carbon surface.

\subsection{Surface acidity by ammonia-temperature-programmed desorption $\left(\mathrm{NH}_{3}-\mathrm{TPD}\right)$}

Fig. SI-2 presents the $\mathrm{NH}_{3}$ - TPD profile of as-prepared adsorbents for determination of the surface acidity. The desorbed ammonia at three temperature range of $200-300^{\circ} \mathrm{C}, 400-600^{\circ} \mathrm{C}$ and $800-1000^{\circ} \mathrm{C}$ correspond to $\mathrm{NH}_{3}$ desorption on weak, moderate and strong acid sites respectively (Glorius et al. 2018; Tanimu et al. 2019). Adsorbent bare AC exhibits two broad desorption peaks at $410^{\circ} \mathrm{C}$, and $844^{\circ} \mathrm{C}$ describing two acidic sites of different strength where the former low-temperature $\mathrm{NH}_{3}$ desorption acid site corresponds to lower strength and the later high-temperature $\mathrm{NH}_{3}$ desorption represents strong acid sites corresponding to both Lewis and Brønsted acidic sites. Similarly, a single broad diffuse peak is observed at $485^{\circ} \mathrm{C}$ for the adsorbent AC-N. This peak is attributed to moderate acid sites. In contrast, AC$\mathrm{N}$-Mo showed two peaks at $421^{\circ} \mathrm{C}$ and $856^{\circ} \mathrm{C}$, the broad diffuse peak at low temperature is ascribed to moderate acid sites and the peak at narrower elevated temperature corresponds to the strongest Lewis and Brønsted acidic sites on the carbon surfaces (Ferenc Lónyi 2001; Ganiyu et al. 2017). The carbon composite AC-Mo also displayed three broad desorption maxima at $214{ }^{\circ} \mathrm{C}, 400^{\circ} \mathrm{C}$ and $847^{\circ} \mathrm{C}$ corresponding to acid sites of low, medium and strong acidic strength respectively. Table SI-2 enumerates the calculated acidic sites where we have AC-N-Mo displayed the strongest acidic sites of $1.84 \mathrm{mmol} / \mathrm{g}$ at STP attributed to the synergy effect of nitrogen heteroatom and hence aided well dispersion of weakly acidic molybdenum nanoparticles on carbon surface (Mabena et al. 2018). This further provide a clear picture why AC-N-Mo gave higher enhancement of the DBT uptake.

\subsection{Adsorption evaluation of the developed adsorbents}

Adsorption efficiency of pure AC, AC-N, AC-N-Mo and AC-Mo were studied in a batch system at room temperature (RT) as a function of time for a simulated diesel fuel composed of isooctane and $100 \mathrm{mg}$ $\mathrm{S} / \mathrm{L}$ as DBT. The effect of carbon surface modification with heteroatom $(\mathrm{N})$ and molybdenum were also 
observed for efficient DBT removal at initial concentration of $100 \mathrm{mg}-\mathrm{S} / \mathrm{L}$. It is obvious from Fig. 4A that more than $70 \%$ of DBT is adsorbed by as-prepared adsorbents in the first 60 min of equilibration. A relatively much slower adsorption process that continues to $24 \mathrm{~h}$ is observed after the fast adsorption process of the first $60 \mathrm{~min}$. At $24 \mathrm{~h}, \mathrm{DBT}$ uptake reaches a constant value of approximately $90 \%$ for AC, AC-N, and AC-Mo while AC-N-Mo reached a climax value of $99.7 \%$. Thus, $24 \mathrm{~h}$ was taken as equilibrium contact time. The adsorption capacity of AC, AC-N, AC-N-Mo and AC-Mo at $24 \mathrm{~h}$ correspond to $17.96 \mathrm{mg}$ $\mathrm{S} / \mathrm{g}, 17.84 \mathrm{mg}-\mathrm{S} / \mathrm{g}, 19.94$ and $17.92 \mathrm{mg}-\mathrm{S} / \mathrm{g}$ respectively. Adsorption efficiency of bare carbon in the first $15 \mathrm{~min}$ is $75 \%$ and gradually increased to $89.8 \%$ at $24 \mathrm{~h}$. This adsorption breakthrough at the shortest possible time was ascribed to its high surface area of $1027 \mathrm{~m}^{2} / \mathrm{g}$. On the other hand, the DBT uptake of unmodified carbon at interval of time after $360 \mathrm{~min}$ was relatively insignificant and was attributed to transition pores saturation with DBT molecules. AC-N-Mo adsorbent DBT uptake is $62 \%$ in the first 15 min but increase significantly to almost $100 \%$ at $24 \mathrm{~h}$. This adsorption breakthrough capacity could be attributed to both heteroatom and metal modification in that heteroatom allowed a complete dispersion of molybdenum on carbon surfaces to facilitate sulfur-metal interaction through $\pi$-complexation and increased the attachment of oxygen containing functional group (Ganiyu et al. 2016; Danmaliki and Saleh 2017). This is confirmed in the FTIR, XPS, XRD and TPD results. The adsorption efficiency follows the order of AC-N-Mo > AC-Mo > AC > AC-N. The chemistry behind this form of adsorption is that metal ions form $\sigma$-bonds with the s-orbitals and the d-orbitals will back-donate electron density to the antibonding $\pi$ - orbitals in the sulfur containing ring of dibenzothiophene (Saleh et al. 2016). It should be mentioned also that the nitrogen heteroatom $(\mathrm{N})$ influenced well dispersion of metal loading on the surface of AC. Table 2 shows the comparison of adsorption capacities of DBT from model oil on different AC adsorbents. It was discovered that molybdenum modified nitrogen doped activated carbon AC-N-Mo showed a moderately higher adsorption capacities when compared with adsorbents that were reported in a similar research papers (Ganiyu et al. 2016; Saleh and Danmaliki 2016). Whereas, some authors have reported a higher adsorption capacities for DBT as compared to this current study (Nazal et al. 2019; Yaseen et al. 2021).

Table 2: Comparison of adsorption capacities of DBT from model oil on different AC adsorbents 


\begin{tabular}{|c|c|c|c|c|}
\hline $\mathrm{Al}-\mathrm{AC}$ & $\begin{array}{l}\text { Batch } \\
\text { mode }\end{array}$ & 14.19 & Isooctane & (Ganiyu et al. 2016) \\
\hline $\mathrm{AC} / \mathrm{Ce} / \mathrm{Fe} /$ & $\begin{array}{l}\text { Batch } \\
\text { mode }\end{array}$ & 16.63 & $\begin{array}{l}\text { n- } \\
\text { Hexane/toluene }\end{array}$ & $\begin{array}{l}\text { (Danmaliki and } \\
\text { Saleh 2017) }\end{array}$ \\
\hline $\begin{array}{l}\text { AC }-\mathrm{Cu} \mathrm{Y} \\
\text { zeolite }\end{array}$ & $\begin{array}{l}\text { Fixed } \\
\text { bed }\end{array}$ & 5.0 & $\begin{array}{l}\mathrm{n}- \\
\text { Decane/toluene }\end{array}$ & (Hadi 2014) \\
\hline $\mathrm{ACFH}^{\mathrm{a}}$ & $\begin{array}{l}\text { Batch } \\
\text { mode }\end{array}$ & 19.0 & n-Hexane & $\begin{array}{l}\text { (Moosavi et al. } \\
\text { 2012) }\end{array}$ \\
\hline $\begin{array}{l}\mathrm{ACFH}- \\
\mathrm{Cu}(1)^{+b}\end{array}$ & $\begin{array}{l}\text { Batch } \\
\text { mode }\end{array}$ & 14.0 & n-Hexane & $\begin{array}{l}\text { (Moosavi et al. } \\
\text { 2012) }\end{array}$ \\
\hline $\mathrm{AC}-\mathrm{MnO}_{2}$ & $\begin{array}{l}\text { Batch } \\
\text { mode }\end{array}$ & 43.8 & n-Heptane & $\begin{array}{l}\text { (Abu Safieh et al. } \\
2015 \text { ) }\end{array}$ \\
\hline $\mathrm{AC} / \gamma-\mathrm{Fe}_{2} \mathrm{O}_{3}$ & $\begin{array}{l}\text { Batch } \\
\text { mode }\end{array}$ & 38.0 & n-Hexane & (Fayazi et al. 2015) \\
\hline Co/ATGAC ${ }^{\mathrm{c}}$ & $\begin{array}{l}\text { Batch } \\
\text { mode }\end{array}$ & 37.6 & Isooctane & $\begin{array}{l}\text { (Sikarwar et al. } \\
\text { 2018) }\end{array}$ \\
\hline ACAL $5^{d}$ & $\begin{array}{l}\text { Batch } \\
\text { mode }\end{array}$ & 84.5 & n-Hexane & (Nazal et al. 2019) \\
\hline $\mathrm{AC}$ & $\begin{array}{l}\text { Batch } \\
\text { mode }\end{array}$ & 16.63 & $\begin{array}{l}\text { n- } \\
\text { Hexane/toluene }\end{array}$ & $\begin{array}{l}\text { (Saleh and } \\
\text { Danmaliki 2016) }\end{array}$ \\
\hline$A g N P^{k p} / A C^{d}$ & $\begin{array}{l}\text { Batch } \\
\text { mode }\end{array}$ & 25.7 & n-Heptane & (Olajire et al. 2017) \\
\hline $\mathrm{Zn} / \mathrm{AC}$ & $\begin{array}{l}\text { Batch } \\
\text { mode }\end{array}$ & 90.09 & n-Heptane & $\begin{array}{l}\text { (Yaseen et al. } \\
\text { 2021) }\end{array}$ \\
\hline AC-N-Mo & $\begin{array}{l}\text { Batch } \\
\text { mode }\end{array}$ & 19.94 & $”$ & This work \\
\hline
\end{tabular}

aactivated carbon fiber thermally treated, bactivated carbon thermally treated modified with copper cation ${ }^{\mathrm{c}} 1$ wt \% acetic-acid-treated cobalt-modified activated carbon dactivated carbon loaded with $5 \%$ aluminum and dactivated carbon modified with silver nanoparticles synthesized from Cola nitida plant.

\subsection{Effect on initial concentration on maximum adsorption capacity}


Adsorption capacity breakthrough was studied on the prepared adsorbents where the initial concentration of DBT in a simulated fuel was varied between $50-200 \mathrm{mg}-\mathrm{S} / \mathrm{L}$ as a function of time under the working condition of room temperature and fixed adsorbent dosage. Fig. 4B shows the equilibrium maximum sulfur adsorbed by AC-N-Mo at $24 \mathrm{~h}$ equilibration time. It was seen that the maximum adsorption capacity of AC-N-Mo for a varied concentration of $50 \mathrm{mg}-\mathrm{S} / \mathrm{L}$ and $100 \mathrm{mg}-\mathrm{S} / \mathrm{L}$ are $89.2 \%$ and $99.7 \%$ respectively corresponding to $8.92 \mathrm{mg}-\mathrm{S} / \mathrm{L}$ and $19.94 \mathrm{mg}-\mathrm{S} / \mathrm{L}$ respectively. The heteroatom-metal modified activated carbon AC-N-Mo displayed higher adsorption efficiency at the varied concentrations owing to higher amount of surface oxygen it has in combination with the enough available acidic sites that aid adsorption of basic organosulfur compounds. However, the highest adsorption capacity dropped between 150 and 200 ppm and the maximum sulfur uptake observed was almost $79 \%$ at these concentrations corresponding to $24.78 \mathrm{mg}-\mathrm{S} / \mathrm{L}$ and $31.94 \mathrm{mg}-\mathrm{S} / \mathrm{L}$ respectively. This could be that the surface acidity being a favorable factor to adsorption breakthrough was consumed beyond initial concentration of $100 \mathrm{ppm}-\mathrm{S}$. It is noteworthy to mention that the adsorbent AC-N-Mo adsorbed about 60 $\%$ DBT at the first 15 min but increases slowly to $24 \mathrm{~h}$ until no further removal was observed. This was attributed to the adsorbent pore size that was larger than the critical diameter of the DBT (Bu et al. 2011).

\subsection{Adsorption performance as a function of sorbent dosage}

The Fig. 5 (A) present effect of adsorbent dosage on the adsorption efficiency of organosulfur compound DBT adsorbed by AC-N-Mo at room temperature as a function of time. It is established that a positive correlation exists between sorbent amount and adsorption efficiency (Danmaliki and Saleh 2017; Olajire et al. 2017; Saleh 2018). In order to determine the optimum sorbent dosage that is an essential parameter in adsorption studies, a trend in adsorption capacity breakthrough was closely examined at room temperature as a function of dosage increment from $0.025 \mathrm{~g}$ to $0.1 \mathrm{~g}$ at fixed concentration of $100 \mathrm{mg}$ $\mathrm{S} / \mathrm{L}$. Expectedly, an increment is observed in the adsorption efficiency of DBT with dosage increment owing to more active sites introduced by the adsorbent's weight at constant process conditions (Srivastav and Srivastava 2009; Xu et al. 2014) and also due to $\pi$ - $\pi$ dispersive interaction between the graphene layer on AC and aromatic ring in DBT (Bu et al. 2011). It is observed that the adsorption affinity for organosulfur compound by AC-N-Mo reached climax at about $99.7 \%$ for the adsorbent dosage of $0.1 \mathrm{~g}$ in $24 \mathrm{~h}$ and no further removal is observed and that formed the basis why adsorbent dosage is restricted to $0.1 \mathrm{~g}$. It is worth mentioning that $0.025 \mathrm{~g}$ adsorbent exhibits the highest adsorption removal performance (percentage of sulfur adsorbed per g-adsorbent dosage) of $70.95 \%$ in $24 \mathrm{~h}$ contact time and in all the varied dosage, fast adsorption is seen in the first $15 \mathrm{~min}$ followed by slight increase till it reached equilibration time of $24 \mathrm{~h}$. AC-N-Mo adsorbent dosage of $0.025 \mathrm{~g}, 0.05 \mathrm{~g}, 0.075 \mathrm{~g}$ and $0.1 \mathrm{~g}$ correspond to $56.76 \mathrm{mg}-\mathrm{S} / \mathrm{g}, 32.32 \mathrm{mg}-\mathrm{S} / \mathrm{g}, 23.95 \mathrm{mg}-\mathrm{S} / \mathrm{g}$ and $19.94 \mathrm{mg}-\mathrm{S} / \mathrm{g}$ respectively. This shows that percentage sulfur removal is inversely proportional to adsorbent dosage as shown in Fig. 5(B). It goes without saying that the sorbent increment promotes higher adsorption efficiency due to multilayer adsorption being minimal, whereas, equilibrium adsorption capacity of sulfur increase with decrease in sorbent dosage as presented in Fig. $\mathbf{5}$ (B) (contact time up to $360 \mathrm{~min}$ is shown). This phenomenon is attributed to large adsorbent mass that could lead to compacting of the system, which will minimize diffusion of DBT analyte to the adsorption sites of the adsorbents (100 mg-S/L). 


\subsection{Effect of 1-methyl isoquinoline on adsorption capacity}

Aromatic compounds such as pyridine and its derivatives, arenes, toluene, naphthalene, etc. are usually coexist in middle distillate oil and have significant tendency to interfere and cause depletion in the adsorption affinity of sulfur containing organic compounds. In light of this, the competitive effect of pyridine derivative (1-methylisoquinoline) on DBT solution was investigated over the best performing adsorbent AC-N-Mo as simulated diesel oil. It should be noted that heterocyclic nitrogen compounds could either be basic or non-basic on the basis of the availability of lone pair (Mathidala and Ogunlaja 2019). Pyridine and its derivatives such as quinoline, acridine are classified as basic nitrogen due to nitrogen lone pair not contributing towards the aromatic system (i.e. nitrogen lone pair is localized). This localized lone pair extends in the ring plane thus responsible for its basicity. On the contrary, nonbasic/neutral heterocyclic nitrogen compounds such as pyrrole and its corresponding derivatives such as indole, carbazole have delocalized lone pair on nitrogen atom that are part of the aromatic system. This reveals the reason nitrogen atom on the basic nitrogen-containing compounds are more basic than their neutral counterparts (Liu et al. 2008). The adsorption removal efficiency of DBT (100 mg-S/L) by AC-NMo was evaluated in the presence of $100 \mathrm{ppm} 1$-methylisoquinoline at room temperature. The percentage removal at the equilibration time of $24 \mathrm{~h}$ in the presence of competitive heterocyclic nitrogen compound is reduced slightly when compared to the adsorption affinity of DBT in the absence of 1methylisoquinoline. The Fig. 6A shows the removal efficiency of the adsorbent with and without the presence of nitrogen-containing heterocyclic compound. It was seen that at $24 \mathrm{~h}$ the highest adsorption capacity achieved is $72.25 \%$ correspond to $14.47 \mathrm{mg}-\mathrm{S} / \mathrm{g}$ adsorbent as compared to $19.94 \mathrm{mg}-\mathrm{S} / \mathrm{g}$ adsorbent attained with DBT only. This impressive DBT uptake in the presence of nitrogen heterocyclic compound showed how selective AC-N-Mo adsorbent is towards the DBT. This performance was ascribed to acid-base interaction between the graphene on $\mathrm{AC}$ and the basic sulfur compounds. The reduction observed in adsorption capacity can be considered as a result of competition between basic heterocyclic nitrogen compounds and the sulfur compounds to be transported towards the pores on the carbon surface. This adsorption of the nitrogen compounds on carbon surface was hindered by the heteroatom nitrogen used to disperse Mo on the sorbent dosage. It is worth mentioning that melamine $(67 \%$ nitrogen) was the source of the nitrogen used to modify AC surface that is also basic and as mentioned above isoquinoline is basic and charge on nitrogen atom is more negative. Thus the principle of like charges repel might prevent the adsorption of 1-methylisoquinoline onto the carbon surface. Liu et al. used DFT theoretical approach to explain selective adsorption capacity of $\mathrm{Cu}(\mathrm{I})$ zeolite adsorbent over heterocyclic nitrogen compounds in terms of adsorption energy in that energetically preferential adsorbate adsorbed on the adsorbent surface which could also be the reason why AC-N-Mo was very selective towards DBT (energetically favorable) in the presence of competitive nitrogen-containing compound (Liu et al. 2007, 2008).

\subsection{Effect of aromatics on DBT removal}

Toluene and naphthalene were added to DBT dissolved in isooctane and adsorption capacity was investigated accordingly following the addition of 5 vol\% each of toluene and naphthalene separately 
into DBT solution and their mixture in a solution containing DBT. Additionally, 10 vol\% toluene was also examined for the maximum adsorption capacity in a solution containing DBT. The adsorption experiments were carried out at the working condition of initial concentration of DBT (100 mg-S/L) at room temperature over a fixed adsorbent weight. It was observed that the adsorption capacity of the best performing adsorbent (AC-N-Mo) reduced drastically in the presence of $5 \%$ toluene at the equilibration time of $24 \mathrm{~h}$ but interestingly, effect of $5 \%$ naphthalene was insignificant. The percentage removal of DBT at $24 \mathrm{~h}$ in the presence of the former (toluene) and later (naphthalene) are $65.52 \%$ and $81.17 \%$ respectively corresponding to 13.11 and $16.03 \mathrm{mg}-\mathrm{S} / \mathrm{g}$ adsorbent respectively as compared to $19.94 \mathrm{mg}$ $\mathrm{S} / \mathrm{g}$ adsorbent achieved for DBT In the absence of the two aromatic hydrocarbons. For the $10 \%$ toluene, maximum adsorption capacity of $9.96 \mathrm{mg}-\mathrm{S} / \mathrm{g}$ adsorbent $(49.78 \%)$ was attained at $24 \mathrm{~h}$. It is quite obvious that the studied adsorbent was very selective towards both of the aromatic compounds but more selective towards DBT in the presence of naphthalene Also, the mixture of toluene and naphthalene (each of the two compounds $5 \%$ by volume) were introduced in DBT solution and maximum adsorption capacity was evaluated at $24 \mathrm{~h}$. The adsorption efficiency attained for DBT was $9.64 \mathrm{mg}-\mathrm{S} / \mathrm{g}$ adsorbent corresponding to $48.20 \%$ sulfur adsorbed. The existence of drastic reduction in the adsorption capacity of the adsorbent with increased aromatic (toluene) different concentrations (vol \%) was attributed to competitive adsorption between DBT and toluene, both possess similar aromatic structure (Bhandari et al. 2006; Wang et al. 2009a). The investigated adsorbent has higher affinity for DBT relative to naphthalene as shown in the Fig. 6B. This sulfur adsorption affinity of the adsorbent could be ascribed not only to the closer size of the DBT molecules to the size of the adsorbent's pores thereby facilitated the preferential trapping of DBT into the adsorbent but also include the fact that DBT has higher molar mass, boiling point dipole moment and aromaticity compared to naphthalene resulting to $\pi-\pi$ interactions and stronger van der Waals with the adsorbent surface. It is also worth mentioning that the basic properties of DBT also played a crucial role in that there exist acid-base interaction between DBT and molybdenum oxide (Lewis acid) on the sorbent surface thereby resulting in elevated adsorption capacity breakthrough of DBT (Nazal et al. 2015). To further understand the inhibiting effects of aromatic on the studied adsorbent, the same vol \% of toluene and naphthalene were added into DBT solution and was investigated. The result obtained as shown in Fig. 6B revealed that increasing aromatics negatively inhibited adsorption capacity of the adsorbent due to higher competitive adsorption between the studied aromatics and DBT (Jha et al. 2019).

\subsection{Adsorption kinetics}

Adsorbents AC, AC-N, AC-N-Mo and AC-Mo were examined at the concentration range of $50-250 \mathrm{mg}$ S/L. To understand adsorption process and pathways, different kinetic models named pseudo-first order, pseudo-second order and intraparticle diffusion were studied. The pseudo-first order is often employed to describe the initial stage of adsorption process, the pseudo-second order provide an insight of the entire adsorption process and the overall adsorption capacity (Anbia and Parvin 2010) and the intraparticle diffusion is employed to determine whether the rate-determining step for each adsorbent is only intraparticle diffusion or not (Saleh et al. 2018). The details of the equation are described in SI. The value 
for and were calculated from the slope and intercept of the plot of In (-) versus $t$ for the pseudo-first order kinetics, the value of $k_{2}$ and were obtained from the slope and intercept of the plot of versus $t$ for the pseudo-second order kinetics respectively as shown in Fig. SI-3. and C were extracted from the slope and intercept of the plot of versus (see Fig SI-5). Table SI-3 showed the summary of the kinetic parameters for the adsorbents studied at the varied sulfur concentration range for both pseudo-first order and pseudo second order kinetics for easy comparison. It is obvious from Table SI-3 that is lower than and that $R^{2}$ value for pseudo-first order are lower than the $R^{2}$ values of pseudo-second order. This implies that the pseudo-second order kinetic is well fitted by the experimental implying that that the overall sorption rate was likely controlled by the chemisorption on the adsorbent's surfaces and this indicates that the specificity of the adsorbate-adsorbent interaction was very high (see Fig. SI-4) (Ho and Mckay 1999). The pseudo second order kinetics model provides an insight on the rate limiting step of a reaction. This could be by chemisorption wherein valence forces are shared or electrons are exchange between the adsorbate and adsorbent (Wang and Wang 2008). The intraparticle diffusion model plot showed that the intra-particle mass transfer properties that is proportional to for the removal of DBT follows the increasing order of AC $<$ AC-N $<$ AC-N-Mo $<$ AC-Mo (see Fig. SI-5). This implies that the adsorbents AC-Mo and AC-N-Mo are more intraparticle diffusion controlled than the AC-N and AC as shown in the $\mathrm{R}^{2}$ values in Table SI-3. In addition, for the fact that the intraparticle diffusion model plots for the removal of sulfurcontaining compound DBT did not pass through the origin reflect that there could be possibility of combination of complex adsorption mechanisms occurring such that intraparticle diffusion is not the only rate-determining step in the adsorption process (Saleh et al. 2018). In addition, Fig. SI-6 shows the change of $S$ concentration in model fuel over time for each adsorbent at $100 \mathrm{mg}-\mathrm{S} / \mathrm{L}$ to give a better understanding of adsorption process.

It can be seen from the comparison Table SI-3 that there are slight difference between both the experimental and calculated and the $\mathrm{R}^{2}$ values are closer to unity describing that the reaction proceed via pseudo second order kinetics.

\subsection{Adsorption isotherm}

Adsorption isotherms of the adsorbents were studied by Langmuir (see equation in SI) and the results are presented in Fig. SI-7 Langmuir isotherm is not only used to quantify and contrast adsorptive capacity of a number of sorbents material but also to describe gas-solid phase adsorption. It balances the relative rates of adsorption and desorption (dynamic equilibrium) with respect to surface coverage. Adsorption and desorption are proportional to the open and cover adsorbent surface respectively (Ayawei et al. 2017). To understand well enough if the reaction is a favorable process which is an integral part of Langmuir isotherm, the below expression in equation $\mathbf{3}$ is used.

$$
R_{L}=\frac{1}{1+K_{L} C_{o}} \ldots \ldots \ldots \ldots 3
$$


Where $R_{L}$ (dimensionless), $K_{L}\left(\mathrm{~L} \mathrm{mg}^{-1}\right)$ and $C_{0}\left(\mathrm{mg} \mathrm{L}^{-1}\right)$ represent separation factor, Langmuir constant and the initial concentration of the adsorbate respectively. The $R_{L}$ value is an essential features of the Langmuir isotherm representing the shape of the isotherm such that if $R_{L}>1$, it implies unfavorable process, $R_{L}=1$ indicates linearity and $0<R_{L}<1$ indicates favorable process (Kenneth et al.). Adsorption isotherms of the adsorbents were studied by Freundlich and the results are presented in Fig. SI-7. The Freundlich explains explain the surface heterogeneity or multilayer sorption, exponential distribution of active sites as well as their energies (Ayawei et al. 2017). The Freundlich equation is given in SI. It is obvious from the Table SI-4 that the data fitted more for the AC and AC-N adsorbents with better correlation coefficient for Langmuir than Freundlich isotherms, while AC-Mo and AC-N-Mo adsorbents show higher $R^{2}$ value that favors the Freundlich isotherm. The $R^{2}$ values for nitrogen modified-AC is comparable, and this sorbent has tendency for both isotherms. This implies that the adsorbent and adsorbate interaction occurred on heterogeneous surface with a well-defined active site and energy, and this is due to its multifunctional surface properties resulted from nitrogen and molybdenum (Langmuir

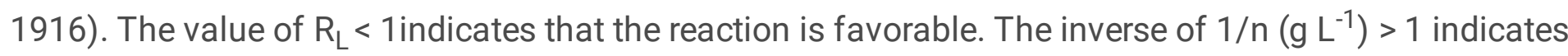
the favorable condition of the adsorption process (V.J.P. Poots, Gordon Mckay 1978). $K_{F}$ and $n$ are both evaluated from the linear plots of $\ln q_{e}$ against $\ln C_{e}$ corresponding to slope and intercept respectively.

\section{Conclusions}

Current work researched on the selective adsorption of DBT using adsorbents synthesized from agricultural waste product by zinc chloride $\left(\mathrm{ZnCl}_{2}\right)$ activation. The best performing adsorbent AC-N-Mo was taken as a potential adsorbent for further evaluation of ADS process. The improved performance can be ascribed to changes in the chemical nature of the adsorbents, the acidic nature of molybdenum (as confirmed in the $\mathrm{NH}_{3}$-TPD) and abundance surface-containing oxygen functional groups. The kinetic studies showed that the reaction proceeded vial pseudo-second order kinetics, indicating that the adsorption process was likely to proceed by chemisorption wherein specificity of adsorbate-adsorbent interaction was very high. While the isotherm revealed that both Freundlich and Langmuir fit the data but Freundlich fit the data more accurately for the best performing adsorbent. It is obvious as demonstrated in this work that preparation of activated carbon from date seeds and its applicability for ultra-deep desulfurization is feasible, promising and worth further studying.

\section{Consent for publication}

All authors have read and gave their consents to the publication of this manuscript entirety.

\section{Declaration of interests}

The authors declare that they have no known competing financial interests or personal relationships that could have appeared to influence the work reported in this paper. 


\section{Declarations}

\section{Consent for publication}

All authors have read and gave their consents to the publication of this manuscript entirety.

\section{Declaration of interests}

The authors declare that they have no known competing financial interests or personal relationships that could have appeared to influence the work reported in this paper.

\section{Authors' contribution}

All authors actively participated in the research activities in both experimental and theoretical ways, data processing and manuscript writing. The manuscript is prepared and approved with all authors. MOA worked majorly on the experimental part and preparation of the first draft under the guidance of SAG, AT engaged in carrying out some characterizations and discussion, while KA and SAG both worked on the logistics of materials for synthesis and characterization, and also participated greatly in the preparation of the drafts.

\section{Funding}

The authors were grateful for the funding received from King Fahd University of Petroleum \& Minerals through project \# DSR SL191003.

\section{Ethical approval}

Not applicable for this work.

\section{Consent to participate}

Not applicable for this work.

\section{Availability of data and materials}

The data that support the findings reported in this work are embedded in the manuscript.

\section{Acknowledgments}

This work was supported through project No. DSR SL191003 by King Fahd University of Petroleum \& Minerals (KFUPM), and it is greatly acknowledged.

\section{References}


Abotsi GMK, Scaroni AW (1989) A review of carbon-supported hydrodesulfurization catalysts. Fuel Process Technol 22:107-133. https://doi.org/10.1016/0378-3820(89)90028-3

Abu Safieh KA, Al-Degs YS, Sunjuk MS, et al (2015) Selective removal of dibenzothiophene from commercial diesel using manganese dioxide-modified activated carbon: A kinetic study. Environ Technol (United Kingdom) 36:98-105. https://doi.org/10.1080/09593330.2014.938125

Aging T, Munajad A (2018) Fourier Transform Infrared ( FTIR ) Spectroscopy Analysis of Transformer Paper in Mineral Oil-Paper Composite Insulation under Accelerated. https://doi.org/10.3390/en11020364

Ahmed I, Jhung SH (2016) Adsorptive desulfurization and denitrogenation using metal-organic frameworks. J Hazard Mater 301:259-276. https://doi.org/10.1016/j.jhazmat.2015.08.045

Al-Qodah Z, Shawabkah R (2009) Production and characterization of granular activated carbon from activated sludge. 26:127-136

Anbia M, Parvin Z (2010) Chemical Engineering Research and Design Desulfurization of fuels by means of a nanoporous carbon adsorbent. 9:641-647. https://doi.org/10.1016/j.cherd.2010.09.014

Ayawei N, Ebelegi AN, Wankasi D (2017) Modelling and Interpretation of Adsorption Isotherms. 2017:

Bhandari VM, Ko CH, Park JG, et al (2006) Desulfurization of diesel using ion-exchanged zeolites. 61:2599-2608. https://doi.org/10.1016/j.ces.2005.11.015

Bhatia S, Sharma DK (2012) Thermophilic desulfurization of dibenzothiophene and different petroleum oils by Klebsiella sp. 13T. Environ Sci Pollut Res 19:3491-3497. https://doi.org/10.1007/s11356-0120884-2

Bojidarka Ivanova TK (2011) Linearly Linearly Polarized Polarized IR I Spectroscopy Spectroscop Polarized IR

Bu J, Loh G, Gwie CG, et al (2011) Desulfurization of diesel fuels by selective adsorption on activated carbons: Competitive adsorption of polycyclic aromatic sulfur heterocycles and polycyclic aromatic hydrocarbons. 166:207-217. https://doi.org/10.1016/j.cej.2010.10.063

By Zhonghua Hu, Madapusi P. Srinivasan A, Ni Y (2000) Preparation of Mesoporous High-Surface-Area Activated Carbon. Adv Mater 2000, 12, No 1. https://doi.org/10.2307/1578122

Coates J (2006) Interpretation of Infrared Spectra , A Practical Approach. 1-23

Danmaliki GI, Saleh TA (2017) Effects of bimetallic Ce / Fe nanoparticles on the desulfurization of thiophenes using activated carbon. Chem Eng J 307:914-927. https://doi.org/10.1016/j.cej.2016.08.143

de Lima FM, de Andrade Borges T, Braga RM, et al (2018) Sulfur removal from model fuel by Zn impregnated retorted shale and with assistance of design of experiments. Environ Sci Pollut Res 
Fagury E, Herta R, Aliaga G (2014) Synthesis of silicon nitride by conventional and microwave carbothermal reduction and nitridation of rice hulls. Adv Powder Technol 25:654-658. https://doi.org/10.1016/j.apt.2013.10.009

Fan WS and W (2013) Nitrogen-containing porous carbons: synthesis and application. 999-1013. https://doi.org/10.1039/c2ta00028h

Fayazi M, Taher MA, Afzali D, Mostafavi A (2015) Removal of Dibenzothiophene Using Activated Carbon/ Y-Fe203 Nano-Composite: Kinetic and Thermodynamic Investigation of the Removal Process

Ferenc Lónyi JV (2001) On the interpretation of the NH 3 -TPD patterns of. 47:

Fu X, Hu X, Yan Z, et al (2016) ChemComm Template-free synthesis of porous graphitic carbon nitride / carbon composite spheres for electrocatalytic oxygen reduction reaction + . 1725-1728. https://doi.org/10.1039/c5cc08897f

Ganiyu SA, Alhooshani K, Sulaiman KO, et al (2016) Influence of aluminium impregnation on activated carbon for enhanced desulfurization of DBT at ambient temperature: Role of surface acidity and textural properties. Chem Eng J 303:489-500. https://doi.org/10.1016/j.cej.2016.06.005

Ganiyu SA, Ali SA, Alhooshani K (2017) RSC Advances Si / Ti ratio on the structural properties, dispersion and catalytic activity. 21943-21952. https://doi.org/10.1039/c7ra01806a

Geng D, Yang S, Zhang Y, et al (2011) Applied Surface Science Nitrogen doping effects on the structure of graphene. Appl Surf Sci 257:9193-9198. https://doi.org/10.1016/j.apsusc.2011.05.131

Ghahramaninezhad M, Ahmadpour A (2020) A new simple protocol for the synthesis of nanohybrid catalyst for oxidative desulfurization of dibenzothiophene. Environ Sci Pollut Res 27:4104-4114. https://doi.org/10.1007/s11356-019-07048-z

Glorius M, Markovits MAC, Breitkopf C (2018) Design of Specific Acid-Base-Properties in CeO 2 -ZrO 2 Mixed Oxides via Templating and Au Modification. 1-25. https://doi.org/10.3390/catal8090358

Guo X, Bao L, Chang L, et al (2019) Influence of modifications on the deep desulfurization behavior of $\mathrm{NaY}$ and Na13X zeolites in gasoline. Environ Sci Pollut Res 26:13138-13146.

https://doi.org/10.1007/s11356-019-04824-9

Hadi NM (2014) Deep Desulfurization of Diesel Fuel by Guard Bed Adsorption of Activated Carbon and Locally Prepared Cu-Y Zeolite. 20:146-159

Haghighi M, Gooneh-farahani S (2020) Insights to the oxidative desulfurization process of fossil fuels over organic and inorganic heterogeneous catalysts: advantages and issues 
Hanif MA, Ibrahim N, Abdul Jalil A (2020) Sulfur dioxide removal: An overview of regenerative flue gas desulfurization and factors affecting desulfurization capacity and sorbent regeneration. Environ Sci Pollut Res 27:27515-27540. https://doi.org/10.1007/s11356-020-09191-4

Ho YS, Mckay G (1999) Pseudo-second order model for sorption processes. 34:451-465

Jha D, Haider MB, Kumar R, et al (2019) Enhanced Adsorptive Desulfurization Using Mongolian Anthracite- Based Activated Carbon. https://doi.org/10.1021/acsomega.9b03432

57. S. W. Sing, D. H. Everett, R. A. W. Haul, L. Moscou, R. A. Pierotti, J. Rouquérol TS (1985) Reporting Physisorption Data for Gas/Solid Systems With Special Reference to the Determination of Surface Area and Porosity. Pure Appl Chem 603:57. https://doi.org/https://doi.org/10.1351/pac198557040603

Kenneth RHALL, Eagleton LEEC, Acrivos A In fixed-bed adsorption under constant- patthern conditions Kim HJ, Bae I, Cho S, et al (2012) Synthesis and characteristics of NH 2 - functionalized polymer films to align and immobilize DNA molecules. Nanoscale Res Lett 7:30. https://doi.org/10.1186/1556-276X-7-30

Lan Y, Li Z, Li D, et al (2019) Applied Surface Science Graphitic carbon nitride synthesized at di ff erent temperatures for enhanced visible-light photodegradation of 2-naphthol. Appl Surf Sci 467-468:411422. https://doi.org/10.1016/j.apsusc.2018.10.152

Langmuir I (1916) The consitution and fundamental properties of solids and liquids. J Am Chem Soc 252:2221-2295. https://doi.org/https://doi.org/10.1021/ja02268a002

Liu D, Gui J, Sun Z (2008) Journal of Molecular Catalysis A: Chemical Adsorption structures of heterocyclic nitrogen compounds over $\mathrm{Cu}$ ( I ) Y zeolite: A first principle study on mechanism of the denitrogenation and the effect of nitrogen compounds on adsorptive desulfurization. 291:17-21. https://doi.org/10.1016/j.molcata.2008.05.014

Liu D, Song L, Gui J, et al (2007) Adsorption structures of heterocyclic sulfur compounds on $\mathrm{Cu}(\mathrm{I}) \mathrm{Y}$ zeolite: a first principle study. 1699-1704

Liu Y, Liu X, Dong W, et al (2017) Efficient Adsorption of Sulfamethazine onto Modified Activated Carbon: A Plausible Adsorption Mechanism. Sci Rep 1-12. https://doi.org/10.1038/s41598-017-12805-6

Lo J, Velo-gala I, Sa M (2013) Surface modifications of activated carbon by gamma irradiation. 7:. https://doi.org/10.1016/j.carbon.2013.09.087

Mabena LF, Sinha S, Mhlanga SD, Coville NJ (2018) Nitrogen-doped carbon nanotubes as a metal catalyst support. 67-77. https://doi.org/10.1007/s13204-011-0013-4 
Mahadevan S, Behera SP, Gnanaprakash G, et al (2012) Journal of Physics and Chemistry of Solids Size distribution of magnetic iron oxide nanoparticles using Warren - Averbach XRD analysis. J Phys Chem Solids 73:867-872. https://doi.org/10.1016/j.jpcs.2012.02.017

Mathidala S, Ogunlaja AS (2019) Selective removal of pyridine in fuel by imprinted polymer ( poly 4-vinyl aniline- co -DVB ) as adsorbent. Pet Sci Technol 37:1691-1703.

https://doi.org/10.1080/10916466.2019.1602641

Min A, Harris AT (2006) Influence of carbon dioxide partial pressure and fluidization velocity on activated carbons prepared from scrap car tyre in a fluidized bed. 61:8050-8059.

https://doi.org/10.1016/j.ces.2006.09.047

Moosavi ES, Dastgheib SA, Karimzadeh R (2012) Adsorption of Thiophenic Compounds from Model Diesel Fuel Using Copper and Nickel Impregnated Activated Carbons. https://doi.org/10.3390/en5104233

Muzic M, Sertic-Bionda K, Gomzi Z (2008) Kinetic and statistical studies of adsorptive desulfurization of diesel fuel on commercial activated carbons. Chem Eng Technol 31:355-364.

https://doi.org/10.1002/ceat.200700341

Namchot W, Jitkarnka S (2016) Impacts of nickel supported on different zeolites on waste tire-derived oil and formation of some petrochemicals. J Anal Appl Pyrolysis 118:86-97.

https://doi.org/10.1016/j.jaap.2016.01.001

Nazal MK, Khaled M, Atieh MA, et al (2019) The nature and kinetics of the adsorption of dibenzothiophene in model diesel fuel on carbonaceous materials loaded with aluminum oxide particles. Arab J Chem 12:3678-3691. https://doi.org/10.1016/j.arabjc.2015.12.003

Nazal MK, Khaled M, Atieh MA, et al (2015) The nature and kinetics of the adsorption of dibenzothiophene in model diesel fuel on carbonaceous materials loaded with aluminum oxide particles. Arab J Chem. https://doi.org/10.1016/j.arabjc.2015.12.003

Olajire AA, Abidemi JJ, Lateef A, Benson NU (2017) Adsorptive desulphurization of model oil by Ag nanoparticles-modified activated carbon prepared from brewer's spent grains. J Environ Chem Eng 5:147-159. https://doi.org/10.1016/j.jece.2016.11.033

Puello-polo E (2014) Nature of the active phase in hydrodesulfurization: molybdenum carbide supported on activated carbon. 5:61-74

Rekos K, Kampouraki ZC, Panou C, et al (2020) Adsorption of DBT and 4,6-DMDBTon nanoporous activated carbons: the role of surface chemistry and the solvent. Environ Sci Pollut Res. https://doi.org/10.1007/s11356-020-08242-0

Roh J (2008) Structural Study of the Activated Carbon Fiber using Laser Raman Spectroscopy. 9:127130

Page 23/30 
Sadare 00, Daramola MO (2019) Adsorptive desulfurization of dibenzothiophene (DBT) in model petroleum distillate using functionalized carbon nanotubes. Environ Sci Pollut Res 26:32746-32758. https://doi.org/10.1007/s11356-019-05953-x

Saleh A (2018) Simultaneous adsorptive desulfurization of diesel fuel over bimetallic nanoparticles loaded on activated carbon. 172:. https://doi.org/10.1016/j.jclepro.2017.11.208

Saleh TA, Al-Hammadi SA, Tanimu A, Alhooshani K (2018) Ultra-deep adsorptive desulfurization of fuels on cobalt and molybdenum nanoparticles loaded on activated carbon derived from waste rubber. J Colloid Interface Sci 513:779-787. https://doi.org/10.1016/j.jcis.2017.11.076

Saleh TA, Danmaliki GI (2016) Adsorptive desulfurization of dibenzothiophene from fuels by rubber tyresderived carbons: Kinetics and isotherms evaluation. Process Saf Environ Prot 102:9-19. https://doi.org/10.1016/j.psep.2016.02.005

Saleh TA, Danmaliki GI, Shuaib TD (2016) Nanocomposites and Hybrid Materials for Adsorptive Desulfurization. pp 129-153

Shi Q, Pan N, Liu P, et al (2010) Characterization of sulfur compounds in oilsands bitumen by methylation followed by positive-ion electrospray ionization and fourier transform ion cyclotron resonance mass spectrometry. Energy and Fuels 24:3014-3019. https://doi.org/10.1021/ef9016174

Sikarwar P, Kumar UKA, Gosu V, Subbaramaiah V (2018) Synergetic Effect of Cobalt-Incorporated AcidActivated GAC for Adsorptive Desulfurization of DBT under Mild Conditions. J Chem Eng Data 63:29752985. https://doi.org/10.1021/acs.jced.8b00249

Sobol PE, Bomben KD, Electronics P, Prairie E Handbook of X-ray Photoelectron Spectroscopy

Song C (2007) Chunshan Song Uday T. Turaga Xiaoliang Ma. 651-661. https://doi.org/10.1081/E-ECHP120007732

Srivastav A, Srivastava VC (2009) Adsorptive desulfurization by activated alumina. 170:1133-1140. https://doi.org/10.1016/j.jhazmat.2009.05.088

Tanimu A, Ganiyu SA, Muhammad S, et al (2019) Sono-Assisted Synthesis and Kinetic Modeling of Nanocrystallite Silicalite-1-NiMo Catalysts for Hydrodesulfurization of Dibenzothiophene: Role of Sonication Time on Support Mesoporosity and Catalytic Activity.

https://doi.org/10.1021/acs.iecr.9b03358

Tireli AA, do Rosário Guimarães I, Mello Mattos de Castro G, et al (2020) Iron and molybdenum mixed oxide supported on Al-PILC for the catalytic oxidative desulfurization of dibenzothiophene in simulated diesel fuel. Environ Sci Pollut Res 27:14963-14976. https://doi.org/10.1007/s11356-020-07961-8 
Tironi A, Trezza MA, Irassar EF, et al (2012) Thermal Treatment of Kaolin: Effect on the Pozzolanic Activity Thermal treatment of kaolin: effect on the pozzolanic activity.

https://doi.org/10.1016/j.mspro.2012.06.046

V.J.P. Poots, Gordon Mckay JJH (1978) Removal of Basic Dye from Effluent Using Wood as an Adsorbent. J Water Pollut Control Fed 50:926-935

Wang J, Xu F, Xie W, et al (2009a) The enhanced adsorption of dibenzothiophene onto cerium / nickelexchanged zeolite Y. 163:538-543. https://doi.org/10.1016/j.jhazmat.2008.07.027

Wang L, Wang A (2008) Adsorption properties of Congo Red from aqueous solution onto surfactantmodified montmorillonite. 160:173-180. https://doi.org/10.1016/j.jhazmat.2008.02.104

Wang Q, Liang XY, Zhang R, et al (2009b) Preparation of polystyrene-based activated carbon spheres and their adsorption of dibenzothiophene. Xinxing Tan Cailiao/ New Carbon Mater 24:55-60.

https://doi.org/10.1016/S1872-5805(08)60036-0

Xiong J, Zhu W, Li H, et al (2015) Carbon-doped porous boron nitride: metal-free adsorbents for sulfur removal from fuels. 12738-12747. https://doi.org/10.1039/c5ta01346a

Xiong L, Yan FCX, Mei P (2012) The adsorption of dibenzothiophene using activated carbon loaded with cerium. 713-719. https://doi.org/10.1007/s10934-011-9523-4

Xiong L, Yan X, Mei P, Engineering E (2010) Synthesis and Characterization of a ZrO 2 / AC Composite as a Novel Adsorbent for Dibenzothiophene. 341-350

Xu X, Zhang S, Li P, Shen Y (2014) Adsorptive desulfurization of liquid Jet-A fuel at ambient conditions with an improved adsorbent for on-board fuel treatment for SOFC applications. Fuel Process Technol 124:140-146. https://doi.org/10.1016/j.fuproc.2014.03.001

Yahya MA, Al-Qodah Z, Ngah CWZ (2015) Agricultural bio-waste materials as potential sustainable precursors used for activated carbon production: A review. Renew Sustain Energy Rev 46:218-235. https://doi.org/10.1016/j.rser.2015.02.051

Yaseen M, Ullah S, Ahmad W, et al (2021) Fabrication of Zn and Mn loaded activated carbon derived from corn cobs for the adsorptive desulfurization of model and real fuel oils. Fuel 284:119102. https://doi.org/10.1016/j.fuel.2020.119102

\section{Figures}



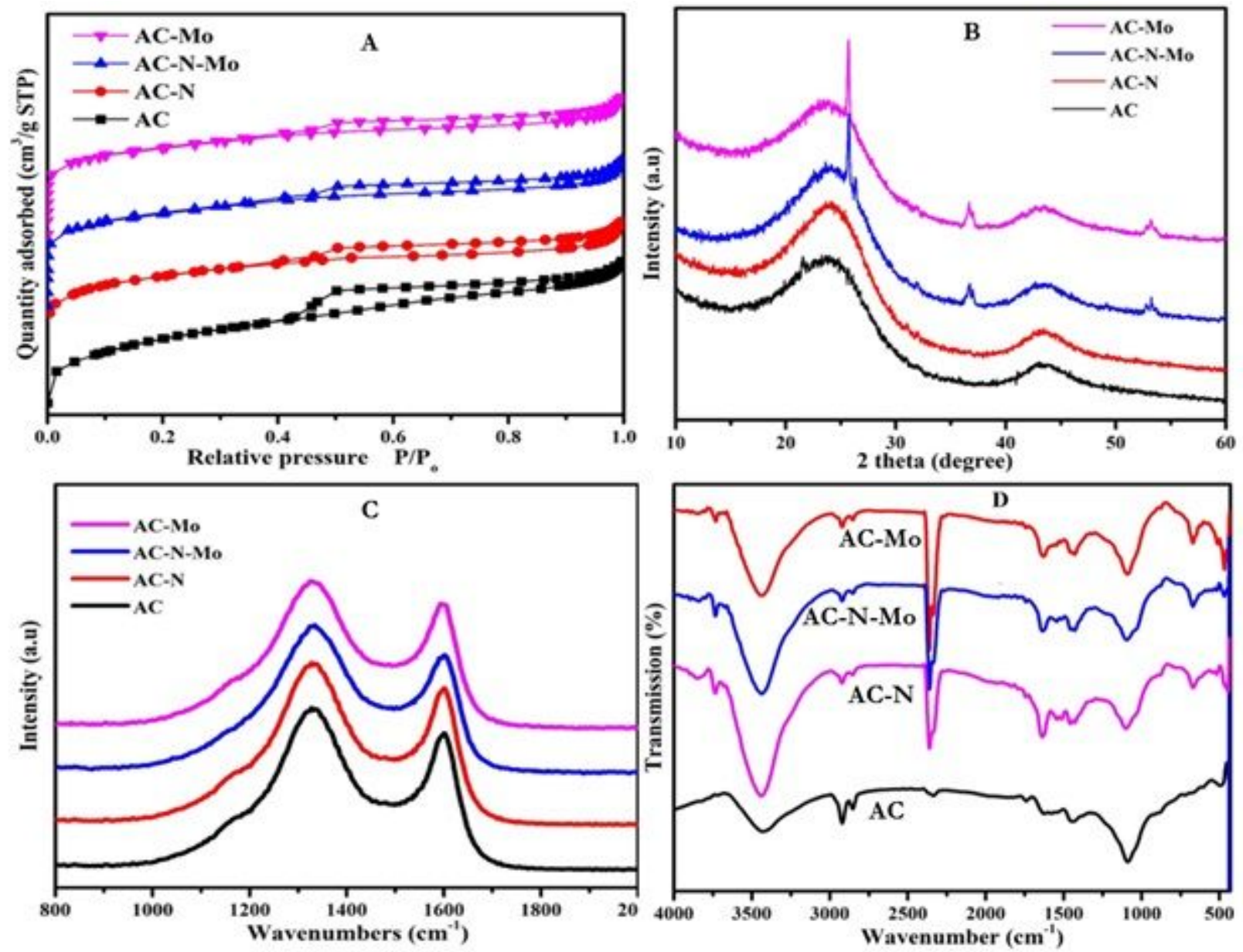

Figure 1

(A) N2 sorption isotherms (B) XRD (C) Raman and (D) FTIR of adsorbents 


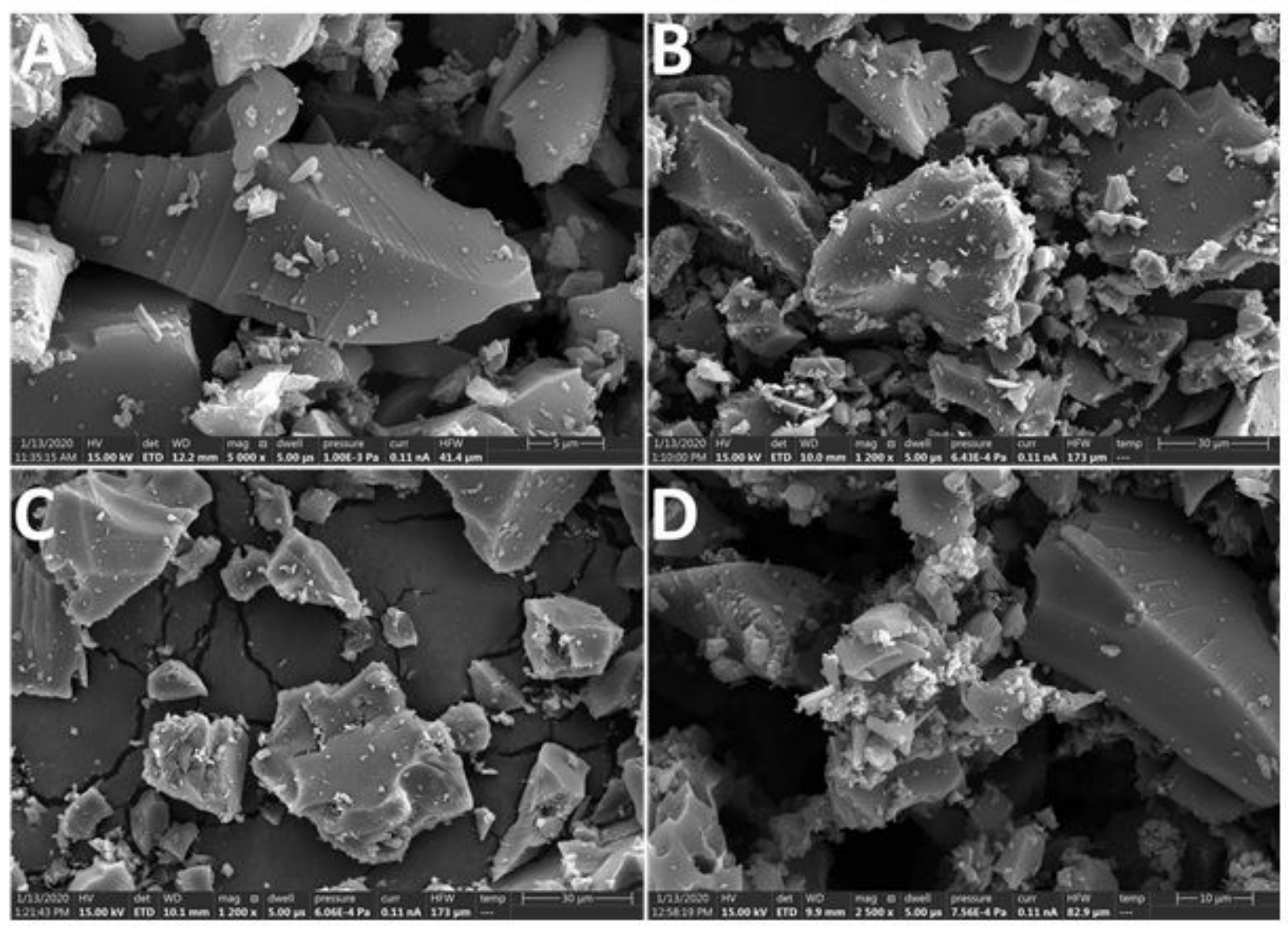

Figure 2

SEM images of adsorbents (A) AC (B)AC-N (C) AC-N-Mo and (D) AC-Mo 

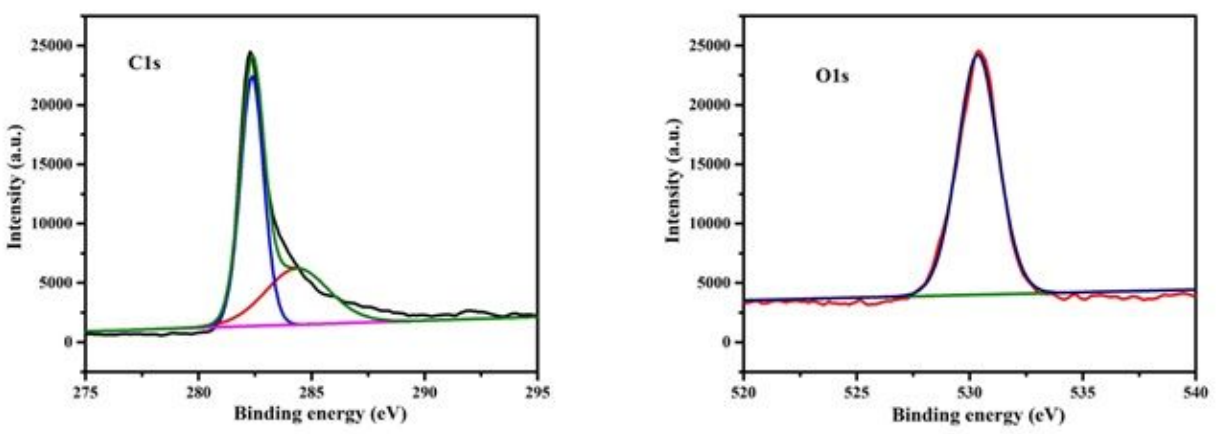

(a):
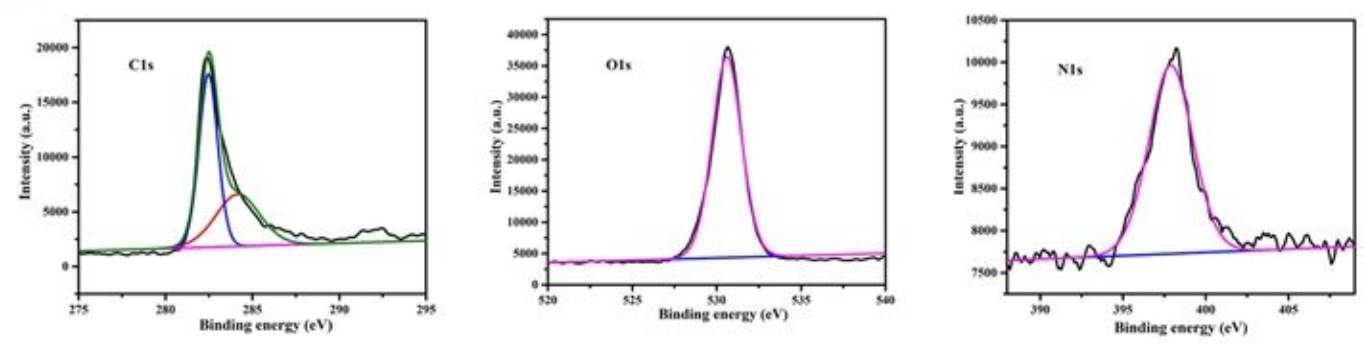

(b):
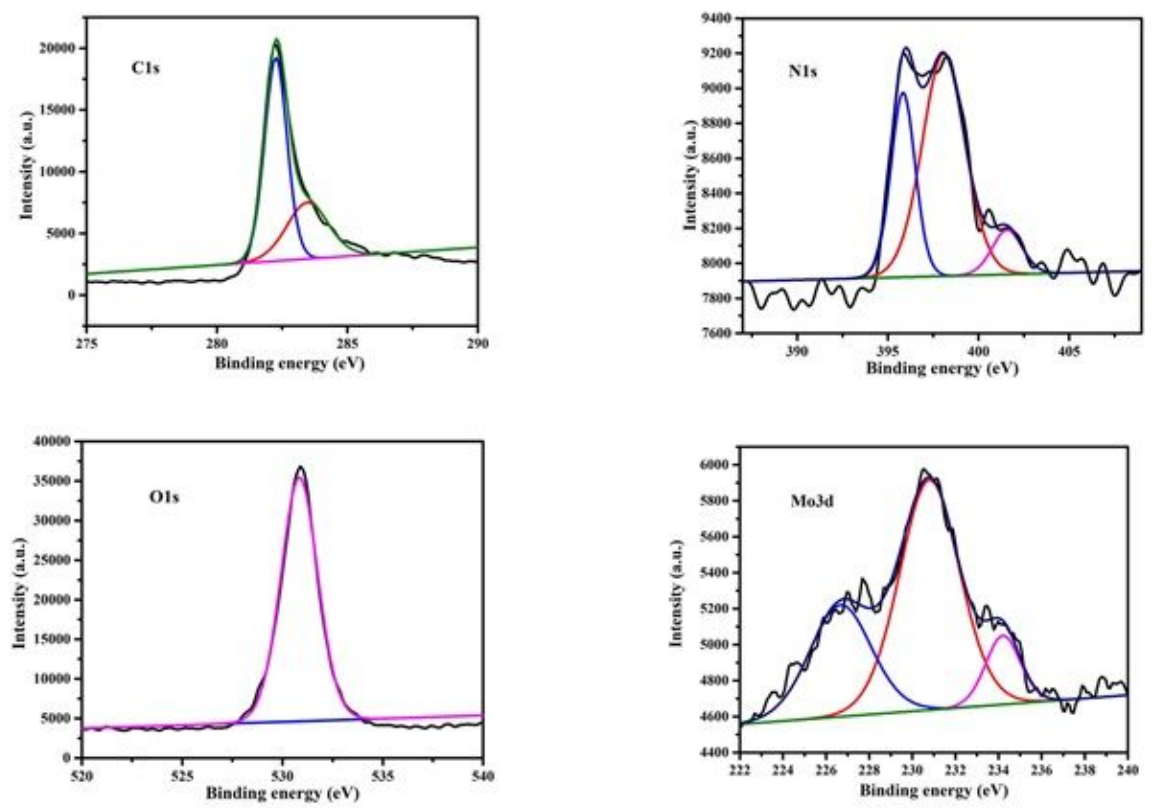

(c):

Figure 3

(a): XPS spectra of C1s and 01s in pure AC. (b): XPS spectra of C1s, 01s and N1s in pure AC-N. (c): XPS spectra of $\mathrm{C} 1 \mathrm{~s}$, 01s N1s and Mo3d in AC-N-Mo 


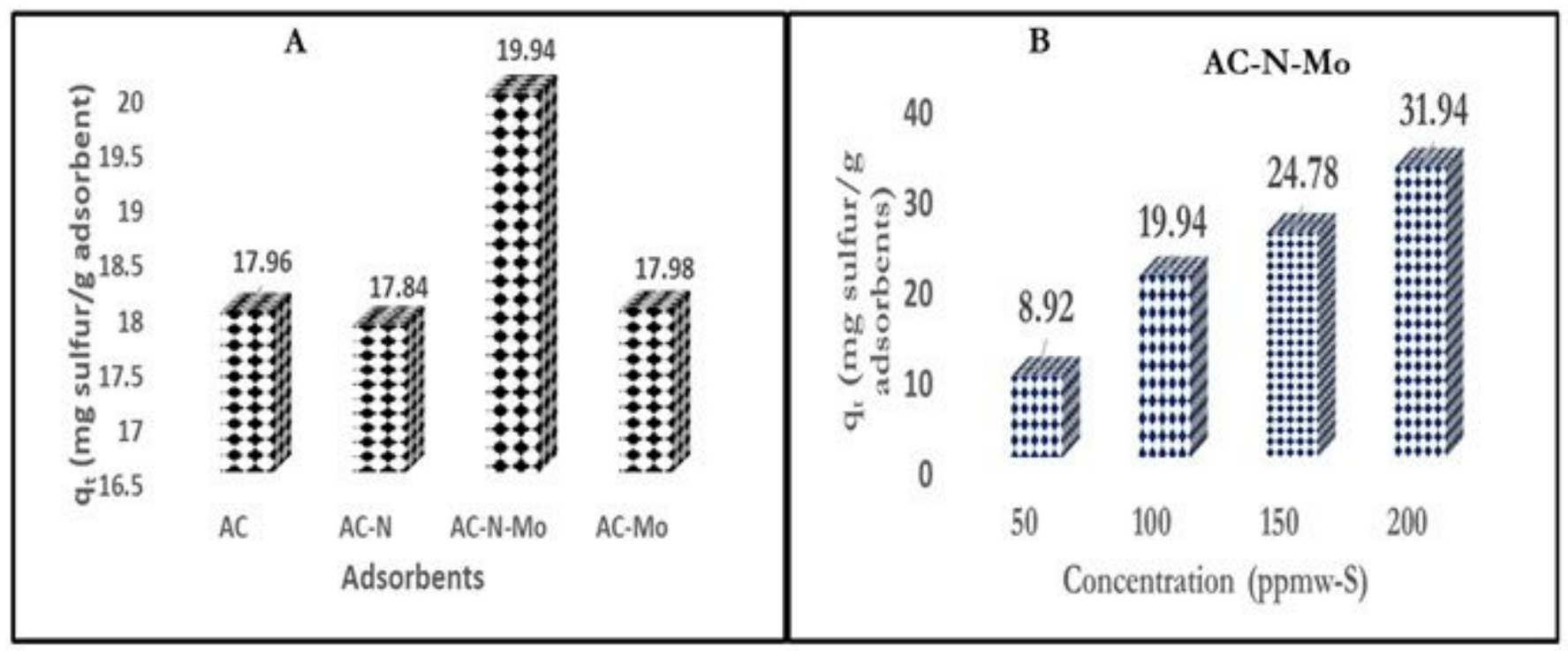

Figure 4

(A) Adsorption capacity of DBT on adsorbents at $100 \mathrm{mg}-\mathrm{S} / \mathrm{L}$ and (B) Effect of initial concentrations (50 - $200 \mathrm{mg}-\mathrm{S} / \mathrm{L}$ ) on the AC-N-Mo. (adsorbent dosage of $100 \mathrm{mg}, 20 \mathrm{~mL}$ of model fuel and contact time of $24 \mathrm{~h})$
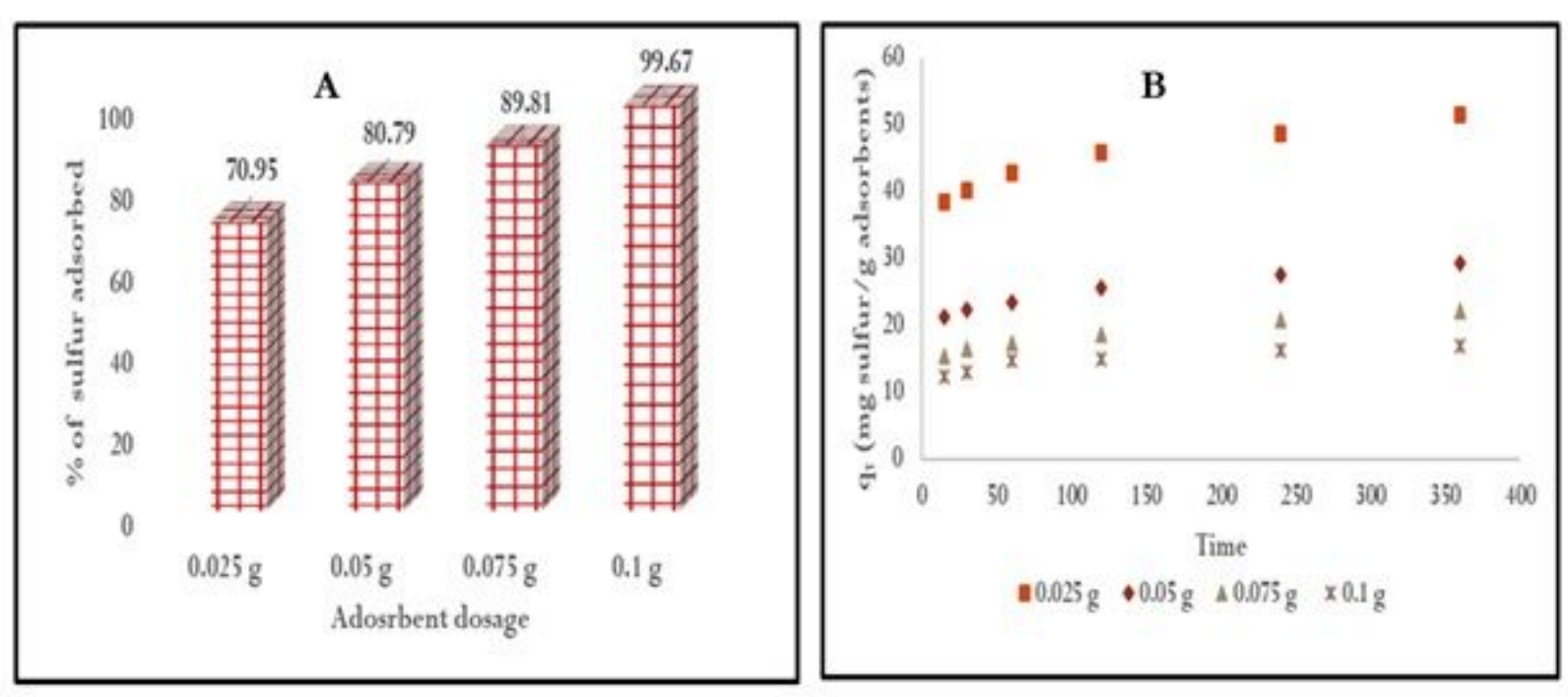

Figure 5

Effect of sorbent dosage as a function of (A) percentage of sulfur adsorbed and (B) equilibrium quantity of sulfur adsorbed (initial conc. $=100 \mathrm{mg}-\mathrm{S} / \mathrm{L}, 20 \mathrm{~mL}$ of isooctane containing DBT and $360 \mathrm{~min}$ contact time 


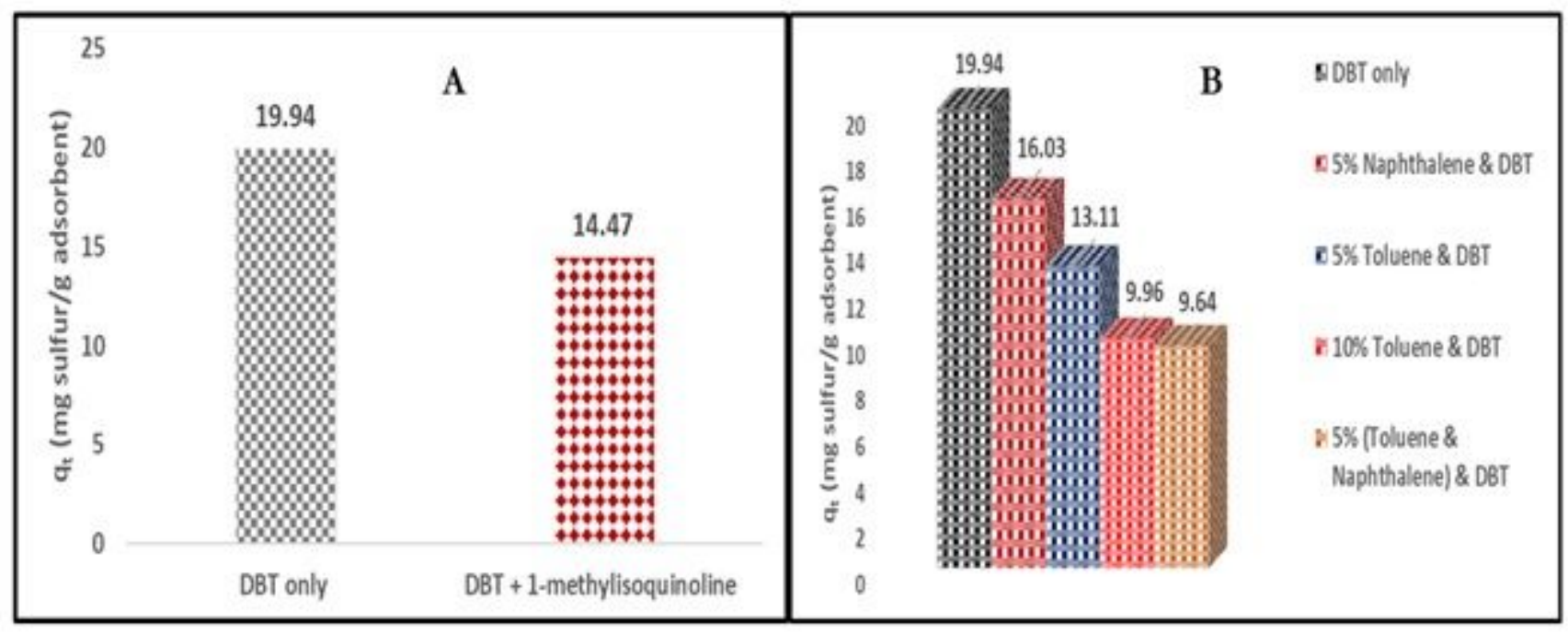

Figure 6

Selectivity performance of $\mathrm{AC}-\mathrm{N}-\mathrm{Mo}$ in the presence of (A) 1-methylisoquinoline and (B) aromatics toluene and naphthalene. $(\mathrm{Co}=100 \mathrm{mg}-\mathrm{S} / \mathrm{L}$, contact time $=24 \mathrm{~h}$ adsorbent dosage $=100 \mathrm{mg}$, and $20 \mathrm{~mL}$ solution of isooctane containing DBT)

\section{Supplementary Files}

This is a list of supplementary files associated with this preprint. Click to download.

- SupplementaryInformationonACNMoManuscript.docx 